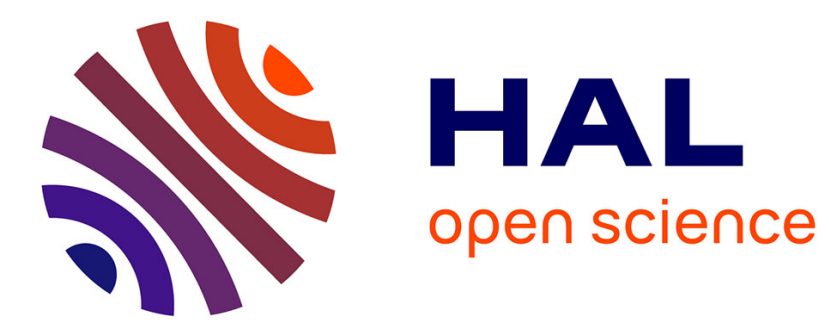

\title{
Thermoplastic polyurethanes (TPUs) with grafted organosilane moieties: A new way of improving thermomechanical behavior
}

Stéphane Dassin, Michel Dumon, Françoise Méchin, Jean-Pierre Pascault

\section{- To cite this version:}

Stéphane Dassin, Michel Dumon, Françoise Méchin, Jean-Pierre Pascault. Thermoplastic polyurethanes (TPUs) with grafted organosilane moieties: A new way of improving thermomechanical behavior. Polymer Engineering and Science, 2002, 42 (8), pp.1724-1739. 10.1002/pen.11066 . hal-02045584

\author{
HAL Id: hal-02045584 \\ https://hal.science/hal-02045584
}

Submitted on 25 Apr 2019

HAL is a multi-disciplinary open access archive for the deposit and dissemination of scientific research documents, whether they are published or not. The documents may come from teaching and research institutions in France or abroad, or from public or private research centers.
L'archive ouverte pluridisciplinaire HAL, est destinée au dépôt et à la diffusion de documents scientifiques de niveau recherche, publiés ou non, émanant des établissements d'enseignement et de recherche français ou étrangers, des laboratoires publics ou privés. 


\title{
THERMOPLASTIC POLYURETHANES (TPUS)
}

WITH GRAFTED ORGANOSILANE MOIETIES:

\section{A NEW WAY OF IMPROVING THERMOMECHANICAL BEHAVIOR}

\author{
Stéphane DASSIN ${ }^{1,2)}$, Michel DUMON ${ }^{1)}$, \\ Françoise MECHIN ${ }^{1{ }^{*}}$, Jean-Pierre PASCAULT ${ }^{1)}$
}

1) Laboratoire des Matériaux Macromoléculaires, UMR CNRS n5627

Institut National des Sciences Appliquées de Lyon, Bât. Jules Verne 20, avenue Albert Einstein, 69621 Villeurbanne Cedex, France

2) GEMOPLAST s.a., Gonas, 38290 Frontonas, France

Keywords: thermoplastic polyurethanes (TPUs), grafting, alkoxysilanes, hydrolytic condensation, thermomechanical properties 


\begin{abstract}
Organosilanes were grafted on thermoplastic polyurethanes (TPUs) using an internal mixer or reactive extrusion. The reaction described here proceeds in two stages, with the help of a diisocyanate as a coupling agent to create allophanate junctions between TPU chains and an aminosilane. Such materials could then be crosslinked by a hydrolytic condensation mechanism, resulting in increased thermomechanical properties. The starting TPU was at first carefully characterized. Using the plastograph, the different stages (reactions between TPU and diisocyanate, isocyanate-grafted TPU and aminosilane, but also between TPU and aminosilane alone) were then studied separately, together with the influence of several essential parameters (time, temperature, rotating speed, etc). Optimal conditions for a well-controlled grafting process were defined, and the different ways of crosslinking the TPU chains were compared.
\end{abstract}




\section{INTRODUCTION}

Thermoplastic polyurethanes (TPUs) are obtained from the reaction of long, soft hydroxyl-terminated oligomers (polyols) with excess diisocyanates and short diols often termed chain extenders. Most of the time, and especially when the synthesis is carried out in two stages, alternating soft and hard segments are obtained and the thermodynamic incompatibility between them usually induces a two-phase structure with soft domains containing mostly the polyol moieties, and hard domains made up of diisocyanate-chain extender sequences (1-8). This particular structure, together with the variety of reagents (chemical nature and molar mass) and stoichiometries that can be used result in versatile engineering properties and a wide range of materials (elastomers, thermoplastics, and both) can be prepared; phase separation being the essential parameter for controlling the final thermomechanical behavior. TPUs are thus widely used for high-performance applications, especially when high tear and tensile strength or good wear and abrasion resistance are required. However, these properties are strongly jeopardized as soon as the service temperature of the material exceeds 70 to $80^{\circ} \mathrm{C}$, mostly because of creep phenomena.

In this work, we tried to improve the working temperature of a commercial TPU by creating well-controlled chemical crosslinks; the idea was to have an easily processable material (i.e. to preserve its thermoplastic character) with an improved thermomechanical behavior. Moreover, the modification had to be feasible via an industrial processing, e.g. reactive extrusion.

Apart from rubber vulcanization, the most common technique to crosslink linear chains is radical crosslinking initiated by peroxides or by high-energy radiation (9). In addition, the use of organo-functional silanes crosslinkable by moisture cure increased after the development of the SIOPLAS ${ }^{\circledR}(10)$ and MONOSIL ${ }^{\circledR}(11)$ processes. In this case vinyltrimethoxysilane (VTMO) is grafted onto linear polyethylene (PE) chains. A peroxide is 
added to promote this reaction, which is usually carried out with an extruder. Other polymers, such as ethylene-propylene copolymers, EPR or ethylene-propylene-diene terpolymers, EPDM $(12,13)$, and even PVC (14-16) can be grafted in the same way. After this processing, the silane-grafted PE can then be crosslinked on demand through the action of water that hydrolyses the alkoxy groups, with subsequent condensation to yield silsesquioxane bonds. Such a process thus allows making self-crosslinkable PE with thermoplastic forming technologies, which are more advantageous in comparison with vulcanization technologies. However a catalyst, generally di- $n$-butyltin dilaurate or an organic acid $(12,17)$ has to be incorporated during the initial processing to obtain acceptable crosslinking rates. Therefore the procedure is unfortunately not suitable for TPUs because the radical VTMO grafting is inadaquate, and also because the usual catalysts described above induce a total degradation of the TPU chains during processing.

A new process for grafting reactive moieties onto TPU chains was recently described in the literature and also by our laboratory $(18,19)$. These works describe the reaction of diisocyanates with urethane groups in TPU chains, which result in the creation of allophanate branching units. In the present work, we tried to perform these reactions in a well-controlled manner, in order to leave pendant isocyanate groups which could then react with aminoalkoxysilanes to generate the same silane-grafted structure obtained for polyethylene via the

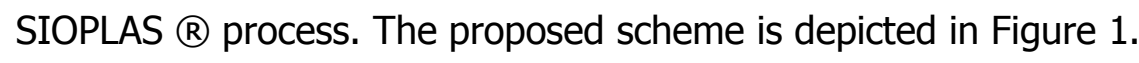




\section{EXPERIMENTAL}

\section{Materials and methods}

The thermoplastic polyurethane (TPU) used in this study was a commercial, polyester-type TPU (Estane 58277, BFGoodrich). The reagents used for grafting were 4,4'diphenylmethane diisocyanate, MDI (Desmodur 44M, Bayer) and 3-amino-propyl trimethoxysilane, $\gamma$-APS (Dynasilan Ammo, Sivento) and were used as received. Both are very fluid liquids at the processing temperature (typically $170-190^{\circ} \mathrm{C}$ ). An important issue was the time for homogeneously mixing the reactive components, since the TPU is still very viscous at such temperatures. However, experiments were quite reproducible and numerous pieces of materials taken from various parts of the blend always led to consistent results.

Size exclusion chromatography (SEC) was performed in THF, using a Waters chromatograph equipped with 3 microstyragel columns (Millipore HR1, HR2 and HR3) with double detection (differential refractometry and UV absorption), and referring to polystyrene standards.

The chemical structure was investigated by ${ }^{1} \mathrm{H}$ and ${ }^{13} \mathrm{C}$ Nuclear Magnetic Resonance (NMR, Bruker 400MHz spectrometer) and Fourier Transform Infra Red spectroscopy (FTIR, Nicolet Magna 550) between 4000 and $400 \mathrm{~cm}^{-1}$.

Differential Scanning Calorimetry (DSC) was carried out using a Mettler TA 3000 calorimeter. The samples $(15-20 \mathrm{mg})$ were placed in aluminum pans and heated up at 10 ${ }^{\circ} \mathrm{C} / \mathrm{min}$ from $-100^{\circ} \mathrm{C}$ to $230^{\circ} \mathrm{C}$.

Dynamic mechanical properties were measured in tensile mode with a Rheometric Scientific RSAII apparatus using a frequency of $1 \mathrm{~Hz}$, from -100 to $230^{\circ} \mathrm{C}\left(3^{\circ} \mathrm{C} / \mathrm{min}\right)$. 


\section{Sample preparation}

Before modification, the TPU was dried 24 hours at $80^{\circ} \mathrm{C}$. For its processing, an internal mixer (HAAKE Plastograph Rheomix 600P) was used to study grafting through torque and internal temperature variation. After a given reaction time, $t$, the modified TPU was recovered and quickly cooled back to room temperature between two plates for further analysis.

Before MDI modification, thin films of the materials were at first analyzed by FTIR to detect any possible NCO groups resulting from chain degradation. After the reaction, several pieces of the TPU/MDI blend were either directly analyzed by SEC, or sometimes immediately placed in a solution of $99 \%$ tetrahydrofuran (THF) and $1 \%$ di- $n$-butylamine (DBA). In so doing, the monoamine neutralizes the residual NCO groups, which could otherwise cause some side and crosslinking post-reactions. As amine groups are in large excess compared with $\mathrm{NCO}$ groups $([\mathrm{NH}] /[\mathrm{NCO}]>20)$, we consider that each isocyanate group reacts with one amine group and that residual MDI is completely transformed into its di-adduct, DBA-MDI-DBA. The torque variation can then be compared with the instantaneous molar mass distribution as a function of the reaction time, $\mathrm{t}$.

As for studies on allophanate formation (20-22) the amounts of grafted and crosslinked structures were evaluated indirectly on the basis of the gel fraction in tetrahydrofuran (THF). With silane it was also possible to evaluate the degree of crosslinking after exposure of the silane-grafted TPU in an oven at $70{ }^{\circ} \mathrm{C}$ with $95 \% \mathrm{RH}$ (relative humidity) for 7 days. The gel content values were determined after extraction with THF for $48 \mathrm{~h}$ by comparison of the chromatographic peak area with that of the unmodified TPU. 


\section{RESULTS AND DISCUSSION}

\section{Characterization of the starting material}

The number average molar mass of the raw TPU was evaluated by SEC ( $\bar{M}_{n}=46000$ $+/-2000$ with respect to a polystyrene calibration). In order to have a better control over the future grafting reactions, we tried at first to have a precise image of the chemical structure of this material, using FIR and mainly ${ }^{1} \mathrm{H}$ and ${ }^{13} \mathrm{C}$ NMR. From these analyses, it could be concluded that the soft segment was based on adipic acid and 1,4-butanediol (BDO), whereas the diisocyanate was 4,4'-diphenylmethane diisocyanate (MDI) extended with BDO to yield the hard segments. More precisely, the peak integrations of the ${ }^{1} \mathrm{H}$ spectrum (Fig.2) were compatible with the structure depicted in Figure 3 and their corresponding attributions indicated in Table 1. From these data, it is indeed not possible to determine separately the lengths of the soft (parameter $\mathrm{m}$ ) and hard (parameter $\mathrm{x}$ ) segments, respectively; however the average length ratio $\mathrm{m} /(\mathrm{x}+1)$ can be calculated. Depending on the peak integration used, it appears that:

$$
1.62<\frac{\mathrm{m}}{\mathrm{x}+1}<1.69 \quad \text { or } \quad \frac{\mathrm{m}}{\mathrm{x}+1} \approx 1.66
$$

From this value, two characteristic features for the starting TPU can be deduced:

i) the urethane equivalent weight, $M_{u}=334 \mathrm{~g} \cdot \mathrm{mol}^{-1}$ (meaning that the average number of urethane bonds per chain is about 140)

ii) the hard segment proportion, about $44 \mathrm{wt} \%$

Such a structure is consistent with the thermal transitions, $\mathrm{T}_{\mathrm{g}}$ (glass transition temperature) and $\mathrm{T}_{\mathrm{m}}$ (melting temperature) determined by DSC. For this TPU, $\mathrm{T}_{\mathrm{g}}$ was measured at $-21^{\circ} \mathrm{C}$ (see Figure $4 a$ ). The melting zone associated with $\mathrm{T}_{\mathrm{m}}$ does not appear as a characteristic narrow endothermic peak as for semi-crystalline polymers, but more as a weak, broad peak between 80 and $160^{\circ} \mathrm{C}$. $\mathrm{T}_{\mathrm{g}}$ is in general about $-70^{\circ} \mathrm{C}$ for pure polyadipates (23), whereas it was found equal to $107^{\circ} \mathrm{C}$ for a pure MDI/BDO hard segment (24); using a 
simple Fox-type equation, and assuming the polymer is totally amorphous and homogeneous, $\mathrm{T}_{\mathrm{g}}$ could be roughly evaluated as:

$$
\frac{1}{T_{g}}=\frac{w_{s}}{T_{g s}}+\frac{w_{h}}{T_{g h}}
$$

With $\mathrm{w}_{\mathrm{s}}=56 \%$ and $\mathrm{w}_{\mathrm{h}}=44 \%$, it comes out that $\mathrm{T}_{\mathrm{g}}=-18^{\circ} \mathrm{C}$. The actual value is only slightly lower: the soft domains are thus far from being pure, but rather a nearly homogeneous mixture of the "soft" and "hard" segments, consistently with their very comparable lengths; while other transitions presumably associated with a small semicrystalline hard domain appear at higher temperature. Both transitions are also visible in the dynamic mechanical spectrum (Fig. 4b). In this graph, it appears clearly that although the mechanical properties of this material are quite good below $70-80^{\circ} \mathrm{C}$, it would be impossible to use it above these temperatures without some modification.

\section{TPU $/ \gamma$-APS systems}

In a first step, we examined the possibility of grafting the organosilane directly onto the TPU chain, without the help of a coupling agent. The TPU was at first "molten" at $170^{\circ} \mathrm{C}$ for $5 \mathrm{~min}$; at the end of this time, no NCO group could be detected by FTIR analysis. Then, $\gamma$-APS $\left(0.16 \mathrm{~mol} / \mathrm{kg} \mathrm{TPU}\right.$, or $\left[\mathrm{NH}_{2}\right] /[$ ureth.] $=0.054)$ was added all at once. Instantaneously, the torque showed a strong decrease resulting from a much more fluid blend. Unfortunately, SEC (Fig. 5) revealed that although $\gamma$-APS had been totally consumed after 5 min, the whole polymer peak had simultaneously moved towards lower molar masses. This can be attributed to exchange reactions between urethane and amine groups, resulting in chain scissions:

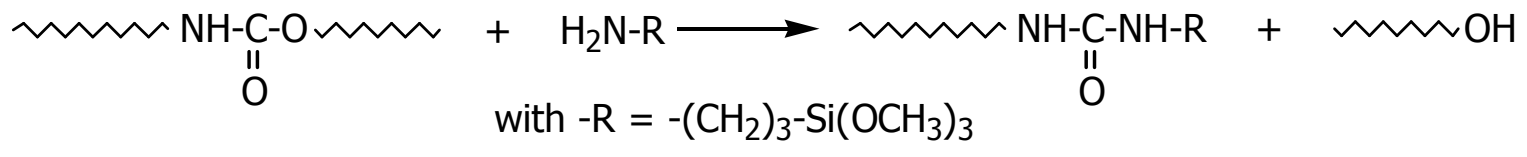

Even after a one-week-long hydrolytic condensation $\left(70^{\circ} \mathrm{C}, 95 \% \mathrm{RH}\right)$, the gel content of this modified material did not exceed 40 to $50 \%$. Consequently, the use of a diisocyanate as coupling agent turned out to be necessary. 


\section{TPU/MDI systems}

In order to avoid the above degradation, the use of a coupling agent is required and it is obviously necessary to add it before the aminosilane. MDI was chosen for this purpose and the systems based only on MDI and the TPU were studied, to be able to define precisely the first stage of the future process.

Typical curves obtained for torque and material temperature as a function of time are shown in Figure 6. During the few minutes that follow MDI loading, the torque increases and finally reaches a plateau. Several samples were collected (see Fig.6) and directly analyzed by SEC, with the corresponding chromatograms displayed in Figure 7. The first sample collected during the torque rise 2 minutes after MDI loading clearly shows some residual diisocyanate; this is less and less visible along the plateau, but in the same time the distribution progressively broadens towards high molar masses with an increasing shoulder at $t_{\text {elution }} \approx$ $22.5 \mathrm{~min}$, until an insoluble fraction finally appears for long reaction times ( $t=15 \mathrm{~min}$, insoluble fraction $=20 \mathrm{wt} \%)$. These observations are compatible with the second isocyanate functions of grafted MDI molecules starting to react with urethane groups born by other TPU chains, yielding first branched molecules with double or triple average molar mass, and finally some insoluble fractions. In order to have a more precise idea of the global MDI conversion during this reaction, new experiments were run and the collected samples were immediately neutralized with excess di- $n$-butylamine and quenched back to room temperature. Even with low amounts of MDI, the resulting DBA-MDI-DBA adduct yields a sharp peak easily detectable in size exclusion chromatograms. This was used to plot the time-conversion curves depicted in Figure 8, obtained with varying rotating speeds.

It appears that MDI conversion is always limited to a value that depends on this speed. The best results are obtained for $100 \mathrm{rpm}$, for which over $90 \%$ of the initial amount of MDI have been consumed at the end of the experiment. The initial reaction rate is also increased when using increasing rotating speeds. In fact, with increasing speed a better 
mixing is rapidly achieved and leads to a more homogeneous system. However, one must keep in mind that increasing shear also induces an increase in the material internal temperature. The effect of the assigned temperature was studied in the same way at 30 $\mathrm{rpm}$, and we observed that for a higher temperature (i.e. $190^{\circ} \mathrm{C}$ ) the torque began to rise but then decreased back to almost its initial level (see Figure 9a). The molar masses of the various samples were measured and plotted as a function of reaction time in Figure 9b; it comes out that $\overline{\mathrm{M}}_{\mathrm{w}}$ increases regularly at $170^{\circ} \mathrm{C}$; whereas it remains almost constant at $190^{\circ} \mathrm{C}$ and increases only slightly at $180^{\circ} \mathrm{C}$. This last behavior might be the most desirable for a well-controlled MDI grafting, since the sharp increase in $\bar{M}_{w}$ at $170^{\circ} \mathrm{C}$ is probably associated with strong chain coupling with a chance of gelation; whereas at $190^{\circ} \mathrm{C}$, rearrangements and chains scissions due to the thermoreversibility of the urethane bond (24-31) presumably become non-negligible and result in partial but irreversible degradation of the material due to the excess NCO groups released in that case.

In any case, the above experiments prove that the first stage of the proposed process is very delicate, and that a compromise needs to be found between three essential parameters: assigned temperature, shear level and MDI reaction time.

\section{TPU/MDI/ $\gamma$-APS systems}

The complete process was finally studied, still with the help of Haake plastograph. A typical curve obtained for successive additions of MDI and $\gamma$-APS to the raw TPU is shown in Figure 10: in this case, MDI was reacted during a time $\mathrm{t}$ and $\gamma$-APS was then added, roughly at the beginning of the torque plateau previously described. At this moment the torque showed a sudden decrease, and then increased back to reach a new plateau.

For a given experiment, the determination of the amounts of diisocyanate and aminosilane needed to obtain the best results is not trivial. It is only possible to define two global stoichiometric ratios, $\mathrm{r}_{1}=[\mathrm{NCO}]_{0} /[\text { urethane }]_{0}=\mathrm{i}_{0} / \mathrm{u}_{0}$, and $\mathrm{r}_{2}=[\mathrm{NCO}]_{0} /\left[\mathrm{NH}_{2}\right]_{0}=\mathrm{i}_{0} / \mathrm{a}_{0}$. 


\section{Determination of the optimal $r_{1}$}

Figure 11 displays the insoluble fraction of the material obtained by grafting the starting TPU with MDI $(\mathrm{t}=2 \mathrm{~min})$ and $\gamma$-APS, after press molding $\left(170^{\circ} \mathrm{C}, 4 \mathrm{~min}\right)$, hydrolysis and condensation of the alkoxy groups $\left(70^{\circ} \mathrm{C} ; 95 \% \mathrm{RH} ; 7\right.$ days). Several $r_{1}$ values were used, while $r_{2}$ was kept constant ( $r_{2}=2$, overall isocyanate excess). Quite logically, it appears that with increasing $r_{1}$, increasing final gel contents are obtained. However we have also checked the insoluble fraction before water reaction, just after press molding. These data are also depicted in Figure 11 , and show that above $r_{1} \approx 0.105$, a small insoluble fraction is already present at the start. This presumably results from premature and uncontrolled gelation due to excess isocyanate functions that induce chain coupling, either by a direct grafting reaction or by reaction with the air moisture; in this case a hydrolyzed NCO group would yield an amine, which should immediately react with another grafted isocyanate moiety. The last part of the increase in the final gel content observed for hydrolysed samples is thus probably due to this initial fraction, which is associated with isocyanate functions that did not react with the aminosilane but can still create a crosslink, hence the change in the slope of the curve. Therefore, a narrow optimal range can be defined for $r_{1}$, which corresponds to the maximal value that will not allow this undesired premature gelation. For $r_{2}=2$ and $t=2$ min, $<r_{1 \text { optimal }} \approx 0.10-0.11$.

\section{Determination of the optimal $r_{2}$}

In the following experiments, a constant value of $r_{1}=0.107$ was used. $\gamma$-APS was added after varying MDI reaction times, $t$, or in different amounts, i.e. with varying $r_{2}$ values.

Considering the effects of $\mathrm{t}$ (see Fig.10), SEC allows the same kind of observation as for experiments with TPU/MDI systems and di- $n$-butylamine (see above and Fig. 7 \& 8): for increasing values of $t$, Figure 12 shows that the polymer peak progressively broadens towards high molar masses (revealing the beginning of chain coupling reactions), while the sharp peak associated with the $\gamma$-APS-MDI- $\gamma$-APS adduct simultaneously decreases. The value 
of $\mathrm{t}$ was then set to $2 \mathrm{~min}$, which corresponds to the beginning of the first torque plateau (Fig.10) with no visible change in the shape of polymer peak (Fig.12).

Varying amounts of aminosilane were then added and reacted with the MDI-grafted TPU for about $3 \mathrm{~min}$ in the plastograph (i.e. the necessary time to reach a stable torque), and the final materials were then collected and analyzed by size exclusion chromatography. If the initial isocyanate concentration is $i_{0}$, then at time $t:$

- concentration of residual (non-reacted) MDI $=\mathrm{x}$

- $\quad$ concentration of reacted MDI $=y=\alpha+\beta$

with - concentration of once-reacted molecules $=\alpha$

and $\quad$ concentration of twice-reacted molecules $=\beta$

- concentration of isocyanate functions $\mathrm{i}=2 \mathrm{x}+\alpha$

with $\quad \mathrm{i}+\alpha+2 \beta=2 \mathrm{x}+2 \alpha+2 \beta=\mathrm{i}_{0}$

The optimal amine amount one should add at this time is thus:

$$
a_{0}=i=2 x+\alpha=i_{0}(1-p)
$$

with $p=$ isocyanate conversion. This means that the optimal value for $r_{2}$ is:

$$
r_{2 \text { optimal }}=\frac{1}{1-p}
$$

Therefore, $a_{0}$ and $r_{2}$ optimal depend on time $t$ and on the reactivity ratio between both isocyanate functions of a MDI molecule towards urethane groups under our experimental conditions. In contrast, using too high or too low amounts of aminosilane can result in material degradation:

- if $a_{0}>$ i (i.e. $r_{2}$ is too low), some residual amine will remain with an initial concentration $a=a_{0}-2 x-\alpha$; these functions can then induce some chain scissions

- if $a_{0}<i$ (i.e. $r_{2}$ is too high), some residual isocyanate functions will be left with a concentration equal to $2 x+\alpha-a_{0}$; as reported above, these functions can cause premature gelation before the end of the full process. 
The above considerations were well illustrated by three experiments using $r_{2}=4 / 3,2$ and 4. In Figure 13, the variation of the torque for these three samples was represented as a function of time, for $r_{1}=0.107$ and $t=2 \mathrm{~min}$. For the highest $r_{2}$ (i.e. the lowest amount of aminosilane), the torque increased to a high value. For $r_{2}=2$, it reached a reasonable plateau, whereas the torque dropped to a non-measurable value for the lowest value of $r_{2}$ (i.e. the highest amount of aminosilane). This last behavior was also partially due to a very bad mixing between the highly viscous MDI-grafted TPU and a high amount of hyperfluid silane. Some improvement was brought by a progressive (instead of instantaneous) $\gamma$-APS addition; but even in this case the final torque was very low.

All these observations were confirmed by the size exclusion chromatograms of the final materials depicted in Figure 14. In this figure, it appears clearly that using $r_{2}=2$, the final mass distribution, although slightly broader than the initial, was centered exactly on the same elution volume; whereas the whole distribution had moved to higher molar masses for $r_{2}=4$, and to lower masses for $r_{2}=4 / 3$

It comes out that using $r_{1}=0.107$ and $t=2 \mathrm{~min}, r_{2}$ optimal $=2$. This is obviously not independent of the fact that with $r_{2}=2$ and $t=2 \mathrm{~min}, r_{1}$ optimal was found in the range 0.10 to 0.11 . In fact, with given temperature and rotating speed, $r_{1}$ and $r_{2}$ are parameters linked by a relation depending on time $t$, but for a given $t$, several $\left(r_{1}, r_{2}\right)$ pairs can presumably fit.

\section{Characterization of the final materials after hydrolytic condensation}

Once grafted with MDI and aminosilane, the TPU was found to be very stable under room atmosphere, in the absence of catalyst. The materials could be kept several months without the appearance of any gel fraction.

\section{Material hydrolysis}

In contrast, the alkoxysilane groups were easily hydrolyzed, simply by aging the materials under a hot and humid atmosphere. For this purpose, $2 \mathrm{~mm}$-thick plates were kept at $70^{\circ} \mathrm{C}$ and $95 \% \mathrm{RH}$ for several days, without hydrolysis catalyst. This procedure was 
chosen to reproduce typical industrial conditions. Figure 15 displays the increase in the insoluble fraction (solvent: THF). The gel content increased rapidly during the first 4 days, after what the crosslinking rate slowed down, yet without completely stopping. The use of a catalyst (stearic acid for instance) allows a faster and complete crosslinking in 1-2 days.

But Figure 15 also shows that the easiest and fastest way of obtaining a complete crosslinking of the material is simply to graft it only with MDI and leave it under room atmosphere; a TPU grafted with MDI $\left(r_{1}=0.107,170^{\circ} \mathrm{C}, 30 \mathrm{rpm}\right)$ and allowed to stand without protection was indeed found to be $100 \%$ crosslinked after 4 days. In fact, the air moisture partially hydrolyses the pendant isocyanate groups:
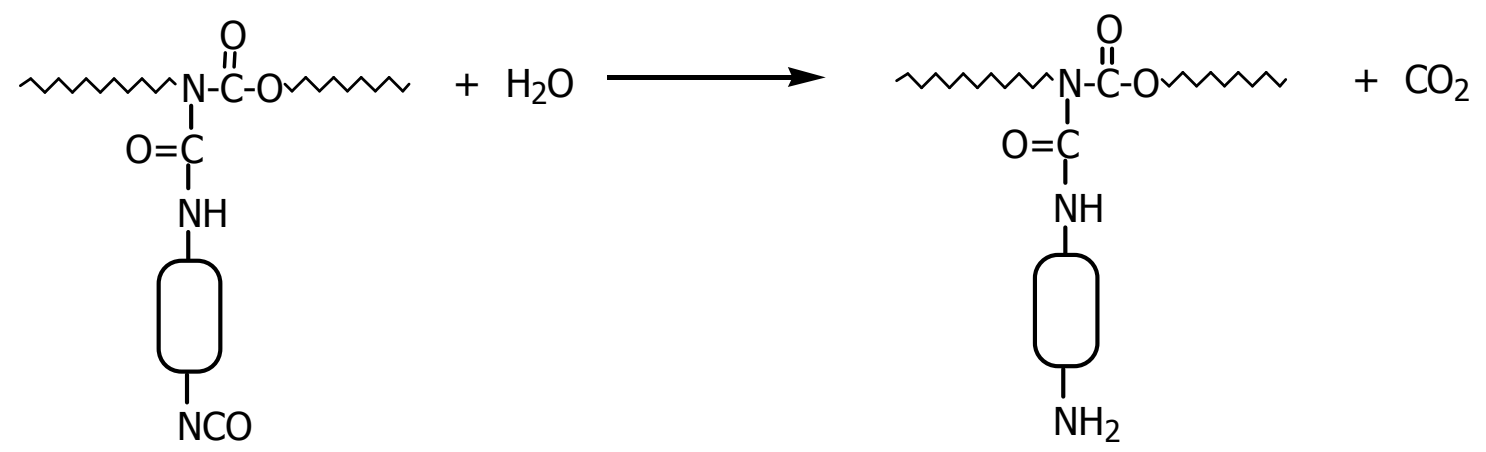

The resulting amine groups rapidly combine with other isocyanate functions, yielding aromatic-aromatic urea groups. This phenomenon finally results in the complete crosslinking of the material. However it is very difficult to control this process, and thus the use of an aminosilane remains necessary if a self-crosslinkable, but still thermoplastic material is desired.

\section{Thermomechanical behavior of the final materials}

The dynamic mechanical properties of the initial and final materials were finally analyzed and compared. Figure 16 displays the storage moduli and loss factors of the starting TPU and of this material grafted either with MDI alone $\left(r_{1}=0.107\right)$, then hydrolyzed in air for several days, or successively with MDI and $\gamma$-APS $\left(r_{1}=0.107, t=2 \min\right.$ and $r_{2}=$ 2) and hydrolyzed in a steam oven $\left(70^{\circ} \mathrm{C}, 95 \% \mathrm{RH}\right)$ for 7 days. For a better comparison, the starting TPU represented here was aged one week under the same conditions, which 
resulted in some plasticization by water, with a lower modulus between $\mathrm{Tg}$ and $70^{\circ} \mathrm{C}$ (see Fig. $4 b$ \& 16).

Both crosslinked materials, instead of flowing above $\sim 120-130^{\circ} \mathrm{C}$, show a new modulus plateau. However the silane-crosslinked polymer has a lower insoluble fraction (about $85 \%$ ) than the MDI-crosslinked sample (100\%). The connecting "bridges" between TPU chains are also longer and softer for the silane-based material. This can explain why the "plateau modulus" of the silane-crosslinked sample above $120^{\circ} \mathrm{C}$ is slightly lower (at $160^{\circ} \mathrm{C}$, $\mathrm{E}^{\prime}=2.73 \mathrm{MPa}$ for this material, whereas the MDI-crosslinked sample shows $\mathrm{E}^{\prime}=3.97 \mathrm{MPa}$ ). However at higher temperatures (above $200^{\circ} \mathrm{C}$ ), a total collapse of the modulus of the MDIcrosslinked sample is observed, while that of the silane-based material seems to hold a little longer: as an illustration, the values of $\tan \delta$ at $200^{\circ} \mathrm{C}$ are respectively 0.73 (MDI) and 0.27 (silane). This behavior probably reveals the destruction of the network structure, which is based on several types of thermally reversible bonds (urethane, allophanate and urea). In fact, both networks contain the same urethane and allophanate bonds, and apart from the stable silsesquioxane linkages the only difference can be found in the nature of the urea bonds, either aromatic-aromatic (MDI-crosslinked material) or aliphatic-aromatic (silanecrosslinked material). In the literature, aromatic-aromatic urethanes have been reported to be thermally less stable than aromatic-aliphatic ones (28); if this was also the case for ureas, then one could account in this way for the slight extra-gain in thermal stability observed for the silane-based material. However the main advantage of this procedure remains the better control of the grafting and crosslinking process.

Finally, the use of increasing amounts of diisocyanate and silane logically results in ever-increasing moduli. Figure 17 shows the values of $E^{\prime}$ obtained for varying amounts of modifiers (with a constant $r_{2}=2$ ). The corresponding gel contents are reported in Figure 11 and Table 2. For the first 4 samples, the curves are quasi-identical up to $\sim 100^{\circ} \mathrm{C}$, with only a very slight difference in the principal mechanical transition ( $\mathrm{Tg}$ increases slightly with the 
amount of modifiers). Then these curves diverge, with the highest amounts of modifiers logically leading to the most crosslinked materials and thus to the highest moduli. The case of the fifth sample (MDI or $\gamma$-APS: $0.40 \mathrm{~mol} / \mathrm{kg}$ TPU, $r_{1}=0.268$ ) is different: the E' curve of this sample is strictly parallel to that obtained with $0.16 \mathrm{~mol} / \mathrm{kg}$ TPU, but well above. This sample, in contrast to all others, already presented an insoluble fraction before water exposure, attributed to some side reactions of the excess diisocyanate molecules during press molding (see above). Apparently, this phenomenon rather affects the first modulus drop (associated with the soft amorphous domains) than the transitions at higher temperatures. As the grafting reaction can only take place on urethane groups and consequently should affect more the mobility of the "hard" segments (HS), these side reactions must thus be enabled only on those HS present in the amorphous phase. In contrast concerning the separated hard domains, grafting would only be possible on their boundaries, without affecting their internal morphology (since the same mechanical transition is always present at the same temperature).

\section{Industrial transposition}

Preliminary attempts (32) to define a near-industrial continuous process were made with a CLEXTRAL twin-screw co-rotating extruder (length/diameter L/D ratio: 36; diameter D $=25 \mathrm{~mm}$ ). The modified material was chilled by water and granulated. With such a processing machine, a better mixing is rapidly achieved, due the high rotating speed (200 rpm). By adjusting the temperature \& screw profiles, output, as well as the MDI feeding zone (hopper or first zone), it will thus be possible to redefine the important parameters (MDI reaction time, $t$, and global stoichiometric ratios, $r_{1}$ and $r_{2}$ ) to obtain the desired grafted material. 


\section{CONCLUSION}

The feasibility of a controlled crosslinking of Thermoplastic PolyUrethanes (TPUs) was demonstrated. Using the classical isocyanate chemistry, it was possible to create well-defined allophanate branching points, which allowed in a second stage the grafting of trialkoxysilane moieties. In this way, "self-crosslinkable" (in the presence of moisture), but still thermoplastic materials could be obtained, that can be considered analogous to polyethylene grafted via the SIOPLAS $®$ process.

The reaction conditions for an optimal grafting were defined with the help of a mixer, by monitoring the torque and internal temperature as well as the molar mass distribution during the process. After pointing out the necessary use of a diisocyanate coupling agent to be able to graft the aminosilane without damaging the material, several important parameters were studied. The mixture temperature, shear level and MDI reaction time are equally essential for a good control of the process. After the first stage, the optimal amount of aminosilane to be added depends on these three parameters, and must be carefully adjusted.

The thermomechanical behavior of these materials was greatly improved once they were crosslinked. A simple grafting with only the diisocyanate is sufficient to obtain a completely crosslinked material; however the grafted materials are unstable, whereas the silane-grafted TPUs remain easily processible until the final crosslinking stage that proceeds on demand in the presence of moisture via a soft and well-controlled reaction.

This new process should now be transposed to more industrial conditions by use of a twin-screw extruder. The parameters studied previously with the mixer can be used to define the new processing conditions; preliminary experiments already gave good results for the preparation of self-crosslinkable TPUs via a continuous process. Moreover, the process designed here should a priori apply to any polymer bearing labile $\mathrm{H}$ atoms; as well as to polymer blends, e.g. in order to crosslink a dispersed phase in situ. 


\section{ACKNOWLEDGEMENTS}

The authors wish to thank Marie-France LLAURO (NMR laboratory, FR CNRS \# 2151, Solaize) for performing the NMR analyses. Financial support from Didier LAGNEAUX (GEMOPLAST s.a., Frontonas), together with fruitful advice and discussions, are gratefully acknowledged. 


\section{REFERENCES}

1- S.L. COOPER, A.V. TOBOLSKY J. Appl. Polym. Sci. 10, 1837 (1966).

2- T.K. KWEI J. Appl. Polym. Sci. 27, 2891 (1982).

3- Y. CAMBERLIN, J.P. PASCAULT J. Polym. Sci. Polym Phys. Ed. 22, 1835 (1984).

4- Z.S. PETROVIC, I. JAVNI J. Polym. Sci. Polym Phys. Ed. 27, 545 (1989).

5- Y. LI, T. GAO, B. CHU Macromolecules 25, 1737 (1992).

6- B. CHU, T. GAO, Y. LI, J. WANG, C.R. DESPER, C.A. BYRNE Macromolecules 25, 5724 (1992).

7- Y. LI, Z. REN, M. ZHAO, H. YANG, B. CHU Macromolecules 26, 612 (1993).

8- Y. LI, W. KANG, J.O. STOFFER, B. CHU, Macromolecules 27, 612 (1994).

9- R.W. REES In Encyclopedia of Polymer Science and Technology, Wiley; New York; 1986; 4: 385 .

10- H.G. SCOTT; US Patent 3,646,155; Midland Silicones Ltd (1972).

11-P. SWARBRICK, W.J. GREEN, C. MAILLEFER; US Patent 4,117,195; BICC Ltd and Maillefer S.A. (1978).

12- A. KUMAR SEN, B. MUKHERJEE, A. S. BHATTACHARYYA, P. P. DE, A. K. BHOWMICK J. Appl. Polym. Sci. 44, 1153 (1992).

13-S. CARTASEGNA Rubber Chem. Technol. 59, 722 (1986).

14- I. KELNAR, M. SCHATZ J. Appl. Polym. Sci. 48, 657 (1993).

15- M. SCHATZ, I. KELNAR, J. VYSOKY Ger. Offen. 3,719,151 (1987).

16- O.S. RODRIGUEZ-FERNANDEZ, M. GILBERT J. Appl. Polym. Sci. 66, 2121 (1997).

17- M. PALMLOF, T. HJERTBERG J. Appl. Polym. Sci. 72, 521 (1999).

18- A. SCHROETER Rubber World 218, 30 (1998).

19-S. LAMBOUR, F. MECHIN, J.P. PASCAULT Polym. Eng. Sci. 42, 68 (2002). 
20-K. DUSEK, M. SPIRKOVA, M. ILAVSKY Makromol. Chem., Macromol. Symp. 45, 87 (1991).

21- M. ILAVSKY, M BOUCHAL, K. DUSEK Polym. Bull. 14, 295 (1985).

22-K. DUSEK, M. SPIRKOVA, M. HAVLICEK Macromolecules 23, 1774 (1990).

23-B. NABETH, I. CORNIGLION, J.P. PASCAULT J. Polym. Sci. Polym Phys. Ed. 34, 401 (1996).

24- L. CUVE, J.P. PASCAULT, G. BOITEUX, G. SEYTRE Polymer 32, 343 (1991).

25-Y. CAMBERLIN, J.P. PASCAULT J. Polym. Sci. Polym. Chem. Ed. 20, 383 (1982).

26- C.D. EISENBACH, M. BAUMGARTNER, C. GÜNTER in Advances in Elastomer and Rubber Elasticity, Plenum Press, New York (1986).

27- J.T. KOBerstein, I. GANCARZ, T.C. CLARKE J. Polym. Sci. Part B Polym. Phys. 24, 2487 (1986).

28-W.P. YANG, C.W. MACOSKO, S.T. WELLINGHOFF Polymer 27, 1235 (1986).

29-K. HERZOG Makromol. Chem., Macromol. Symp. 52, 307 (1991).

30- D. JOEL, A. HAUSER Angew. Makromol. Chem. 217, 191 (1994).

31- T. HENTSCHEL, H. MÜNSTEDT Polymer 42, 3195 (2001).

32-D. LAGNEAUX, S. DASSIN, F. MECHIN, M. DUMON, J.P. PASCAULT World Patent 00/75123 A1; Gemoplast S.A. (2000). 
Table 1: ${ }^{1} \mathrm{H}$ NMR analysis of the unmodified TPU (DMSO d6, $25^{\circ} \mathrm{C}, 400 \mathrm{MHz}$ )

\begin{tabular}{|c|c|c|c|}
\hline proton type $^{\text {a) }}$ & $\delta(\mathbf{p p m})$ & theoretical integration ${ }^{\text {a) }}$ & peak integration \\
\hline $\mathrm{a}$ & 1.57 & $4(2 \mathrm{~m}+1+\mathrm{x})$ & 17.522 \\
$\mathrm{~b}$ & 2.24 & $4 \mathrm{~m}$ & 6.479 \\
$\mathrm{C}$ & 3.73 & $2(\mathrm{x}+1)$ & 1.979 \\
$\mathrm{~d}$ & 4.00 & $4(\mathrm{~m}+1+\mathrm{x})$ & 10.652 \\
$\mathrm{e}$ & 7.03 & $4(\mathrm{x}+1)$ & 4.006 \\
$\mathrm{f}$ & 7.30 & $4(\mathrm{x}+1)$ & 3.995 \\
$\mathrm{~g}$ & 9.45 & $2(\mathrm{x}+1)$ & 1.935 \\
\hline
\end{tabular}

a) according to the structure proposed in Figure 1 
Table 2: Insoluble fractions obtained for the starting TPU and for this TPU grafted with MDI and $\gamma$-APS $\left(r_{2}=2\right)$. All the materials were pressed $\left(170^{\circ} \mathrm{C}, 4 \mathrm{~min}\right)$ and aged for 7 days $\left(70^{\circ} \mathrm{C}\right.$, $95 \% \mathrm{RH})$

\begin{tabular}{|c|c|c|c|}
\hline $\begin{array}{c}\text { modifier amount } \\
\text { (mol/kg TPU) }\end{array}$ & $r_{1}$ & $\begin{array}{l}\text { insoluble fraction } \\
\text { after press molding } \\
\text { (wt\%) }\end{array}$ & $\begin{array}{l}\text { final insoluble } \\
\text { fraction (wt\%) }\end{array}$ \\
\hline 0 & 0 & 0 & 0 \\
\hline 0.04 & 0.027 & 0 & 25 \\
\hline 0.08 & 0.054 & 0 & 48 \\
\hline 0.16 & 0.107 & 0 & 84 \\
\hline 0.40 & 0.268 & 13 & 95 \\
\hline
\end{tabular}




\section{FIGURE CAPTIONS}

Figure 1: Proposed method for the preparation of a self-crosslinkable TPU

Figure 2: ${ }^{1} \mathrm{H}$ NMR spectrum (DMSO d6, $400 \mathrm{MHz}$ ) of the starting TPU

Figure 3: Proposed chemical structure for the starting TPU

Figure 4: DSC analysis [a), $10^{\circ} \mathrm{C} / \mathrm{min}$ ] and dynamic mechanical properties [b), $1 \mathrm{~Hz}$, $3^{\circ} \mathrm{C} / \mathrm{min}$ ] of the raw TPU ( : E'; $\left.\mathbf{\square}: \mathrm{E}^{\prime \prime} ; \mathbf{\Delta}: \tan \cdot\right)$

Figure 5: Size exclusion chromatograms (THF, RI detection) of the starting TPU (- - -) and of the TPU reacted with $\cdot-$ APS alone $\left(170^{\circ} \mathrm{C}, 5 \mathrm{~min}\right)\left(\_\right)$

Figure 6: Material temperature $(-)$ and torque $(-)$ variation observed during the reaction of TPU with MDI $\left([\mathrm{NCO}]_{0} /[\text { urethane }]_{0}=0.107 ; 170^{\circ} \mathrm{C} ; 30 \mathrm{rpm}\right)$ in the Haake plastograph

Figure 7: Size exclusion chromatograms of the initial TPU $(*)$ and of the TPU reacted with MDI $\left([N C O]_{0} /[\text { urethane }]_{0}=0.107 ; 170^{\circ} \mathrm{C} ; 30 \mathrm{rpm}\right)$ for $(\diamond): 2 \mathrm{~min} ;(\Delta): 5 \mathrm{~min} ;(\circ): 7 \mathrm{~min}$; ( ): $15 \mathrm{~min}$; this last sample has only $80 \%$ soluble fraction.

Figure 8: Conversion of MDI molecules deduced from the decrease in the DBA-MDI-DBA adduct peak in size exclusion chromatograms. Reaction temperature: $170^{\circ} \mathrm{C} ; \boldsymbol{\Delta}: 30 \mathrm{rpm}$; - : $60 \mathrm{rpm} ; \bullet: 100 \mathrm{rpm}$.

Figure 9: Effect of the assigned temperature on the grafting of TPU chains with MDI $\left([\mathrm{NCO}]_{0} /[\text { urethane }]_{0}=0.107 ; 30 \mathrm{rpm}\right):$ a) variation of the torque $\left(\mathbf{\Lambda}: 170^{\circ} \mathrm{C} ; \bullet: 190^{\circ} \mathrm{C}\right)$ and internal temperature $\left.\left(\triangle: 170^{\circ} \mathrm{C} ; \mathrm{O}: 190^{\circ} \mathrm{C}\right) ; \mathrm{b}\right)$ variation of the mass average molar mass $\left(\ldots \bullet \ldots: 170^{\circ} \mathrm{C} ;-\mathbf{\square}: 180^{\circ} \mathrm{C} ; .-. \mathbf{\Lambda}-.: 190^{\circ} \mathrm{C}\right)$. 
Figure 10: Material temperature $(-)$ and torque (-) variation observed during the successive additions of MDI $\left([\mathrm{NCO}]_{0} /[\text { urethane }]_{0}=0.107\right)$ and $\cdot-$ APS $\left([\text { amine }]_{0} /[\text { urethane }]_{0}\right.$ $=0.053)$ to the raw $\mathrm{TPU}$ in the Haake plastograph $\left(170^{\circ} \mathrm{C} ; 30 \mathrm{rpm}\right)$

Figure 11: Insoluble fraction obtained for the TPU reacted successively with MDI and --APS $\left(r_{2}=2,170^{\circ} \mathrm{C}, 30 \mathrm{rpm}\right)$ using varying $r_{1}$ values, after : $(\square)$ : press molding $\left(170^{\circ} \mathrm{C}, 4 \mathrm{~min}\right)$; (•) press molding (same conditions), then hydrolysis and condensation of the alkoxysilane groups $\left(70^{\circ} \mathrm{C}, 95 \% \mathrm{RH}, 7\right.$ days). The gray area indicates the optimal $r_{1}$.

Figure 12: Size exclusion chromatograms of the starting TPU ( $\square$ ) and of the TPU reacted $\left(170^{\circ} \mathrm{C}, 30 \mathrm{rpm}\right)$ successively with MDI $\left(r_{1}=0.107\right)$ and $\cdot-$ APS $\left(r_{2}=2\right)$ added after $t=(\bullet)$ : 2min; $(\Delta): 5 \min ;(\diamond): 7 \min$.

Figure 13: Torque variations recorded during the reaction of the TPU $\left(170^{\circ} \mathrm{C}, 30 \mathrm{rpm}\right)$ successively with MDI $\left(r_{1}=0.107, t=2 \min \right)$ and $\cdot-$ APS; $(-): r_{2}=4 ;(-): r_{2}=2 ;(\bullet \bullet \bullet)$ $: r_{2}=4 / 3$

Figure 14: Size exclusion chromatograms of the starting TPU ( $\square)$ and of this TPU reacted in the plastograph $\left(170^{\circ} \mathrm{C}, 30 \mathrm{rpm}\right)$ successively with $\mathrm{MDI}\left(\mathrm{r}_{1}=0.107, \mathrm{t}=2 \mathrm{~min}\right)$ and $\cdot-\mathrm{APS}$; (A) $: r_{2}=4 ;(\circ): r_{2}=2 ;(\bullet): r_{2}=4 / 3$

Figure 15: Insoluble fractions obtained for the TPU grafted with MDI and --APS $\left(r_{1}=\right.$ $\left.0.107 ; r_{2}=2, t=2 \mathrm{~min}\right)$ during hydrolytic condensation $\left(-\bullet, 70^{\circ} \mathrm{C}, 95 \% \mathrm{RH}\right)$. Comparison with a MDI-grafted TPU $\left(r_{1}=0.107\right)$ under room atmosphere $(\ldots . . . .$.$) .$

Figure 16: Storage moduli (a) and loss factors (b) of the starting TPU aged 7 days at $\left(70^{\circ} \mathrm{C}\right.$, 95\%RH) $(\square)$, of the TPU grafted with MDI $\left(r_{1}=0.107\right)$ and hydrolyzed under room atmosphere $(\bullet)$, and of the TPU grafted successively with MDI and --APS $\left(r_{1}=0.107, r_{2}=2\right.$, $\mathrm{t}=2 \mathrm{~min})$ and hydrolyzed $\left(70^{\circ} \mathrm{C}, 95 \% \mathrm{RH}, 7\right.$ days $)(\mathbf{\Delta})$. 
Figure 17: Storage moduli of the starting TPU aged 7 days at $\left(70^{\circ} \mathrm{C}, 95 \% \mathrm{RH}\right)(\square)$ and of the TPU grafted successively with MDI and --APS $\left(r_{2}=2\right)$ using increasing amounts of modifier. Per kg TPU: $(x)$ : $0.04 \mathrm{~mol}$ MDI or --APS $\left(r_{1}=0.027\right) ;(\circ): 0.08 \mathrm{~mol}\left(r_{1}=0.054\right)$; $(\Delta): 0.16 \mathrm{~mol}\left(r_{1}=0.107\right) ;(\diamond): 0.40 \mathrm{~mol}\left(r_{1}=0.268\right)$ 

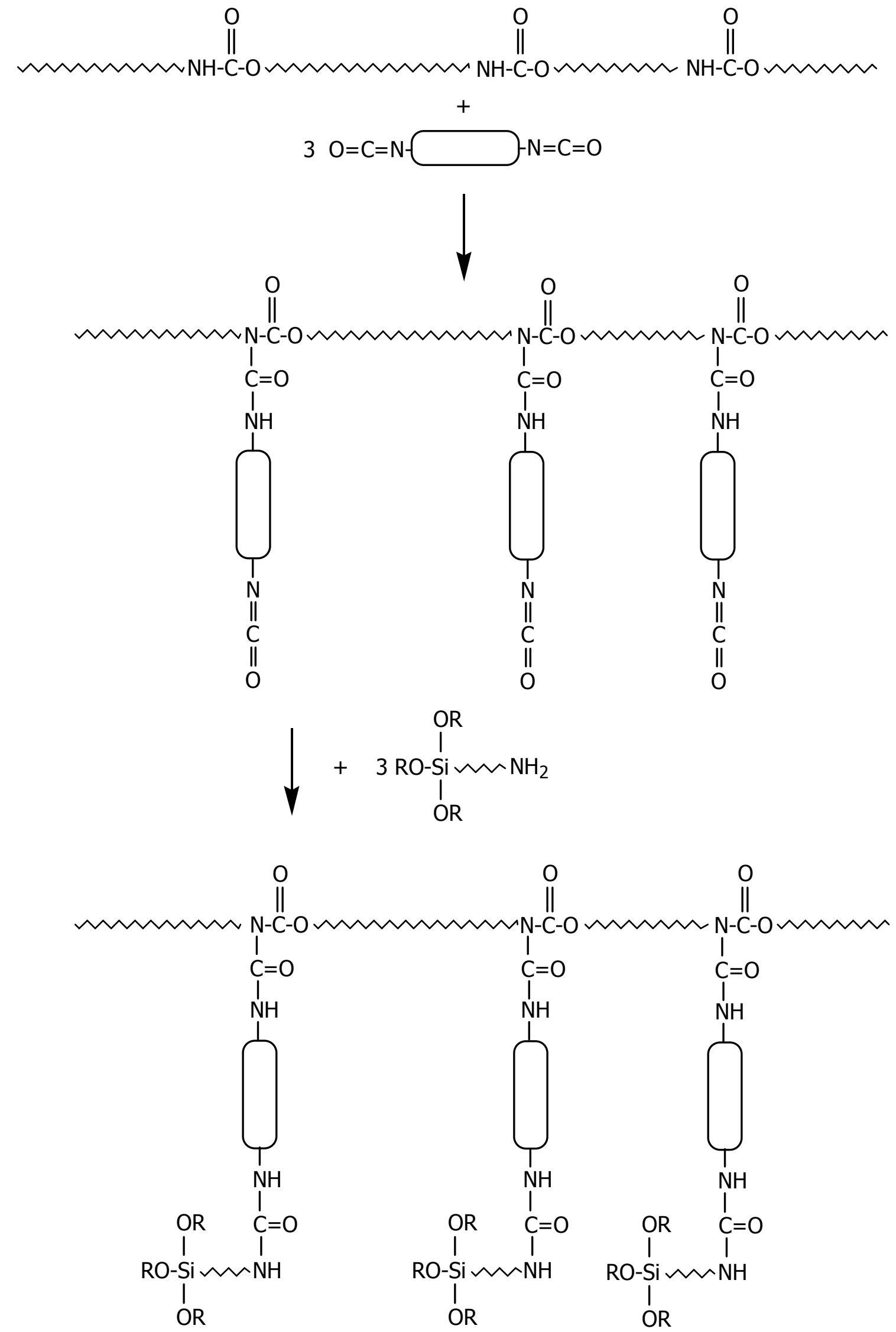

Figure 1: Proposed method for the preparation of a self-crosslinkable TPU 


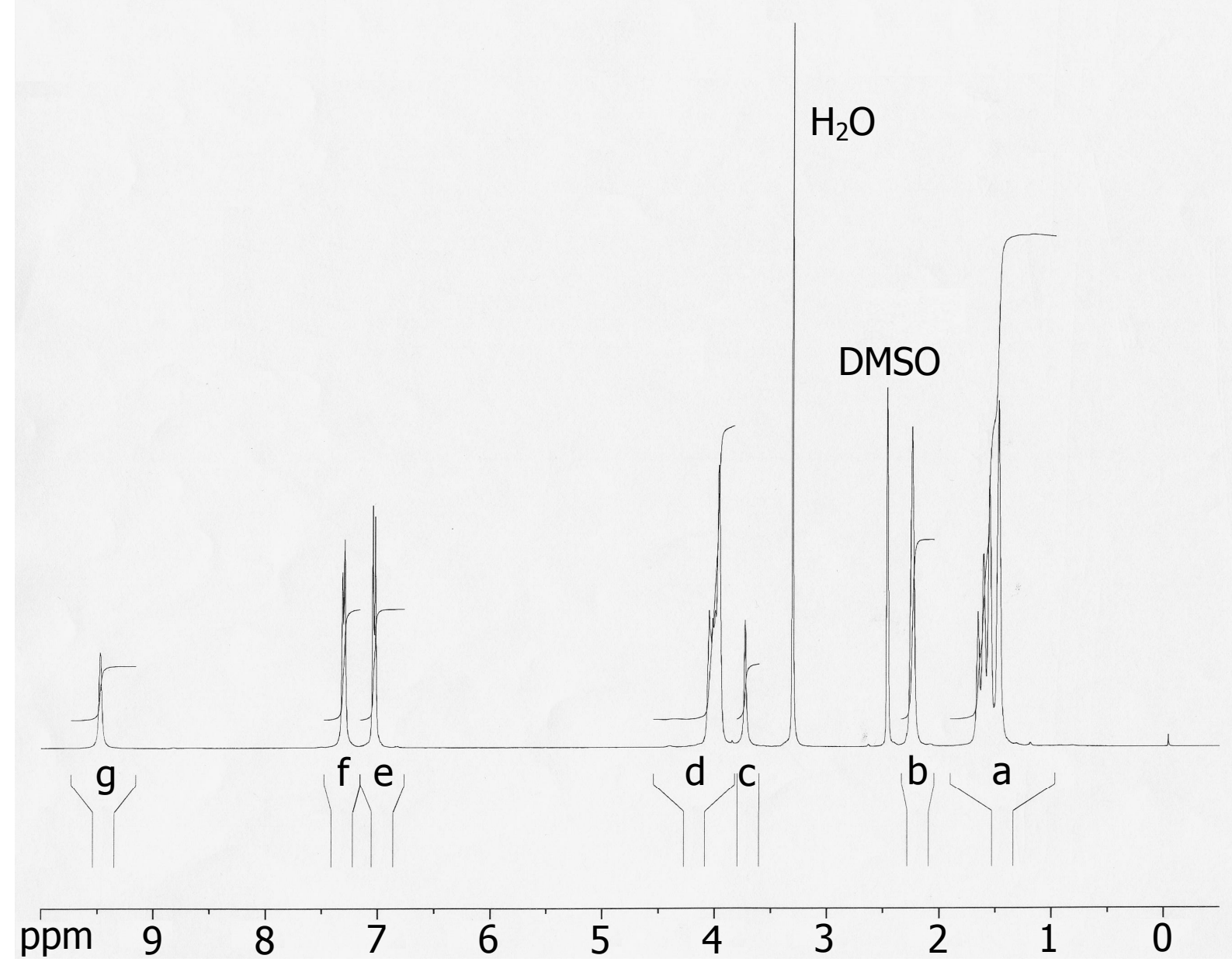

Figure 2: ${ }^{1} \mathrm{H}$ NMR spectrum (DMSO d6, $400 \mathrm{MHz}$ ) of the starting TPU 


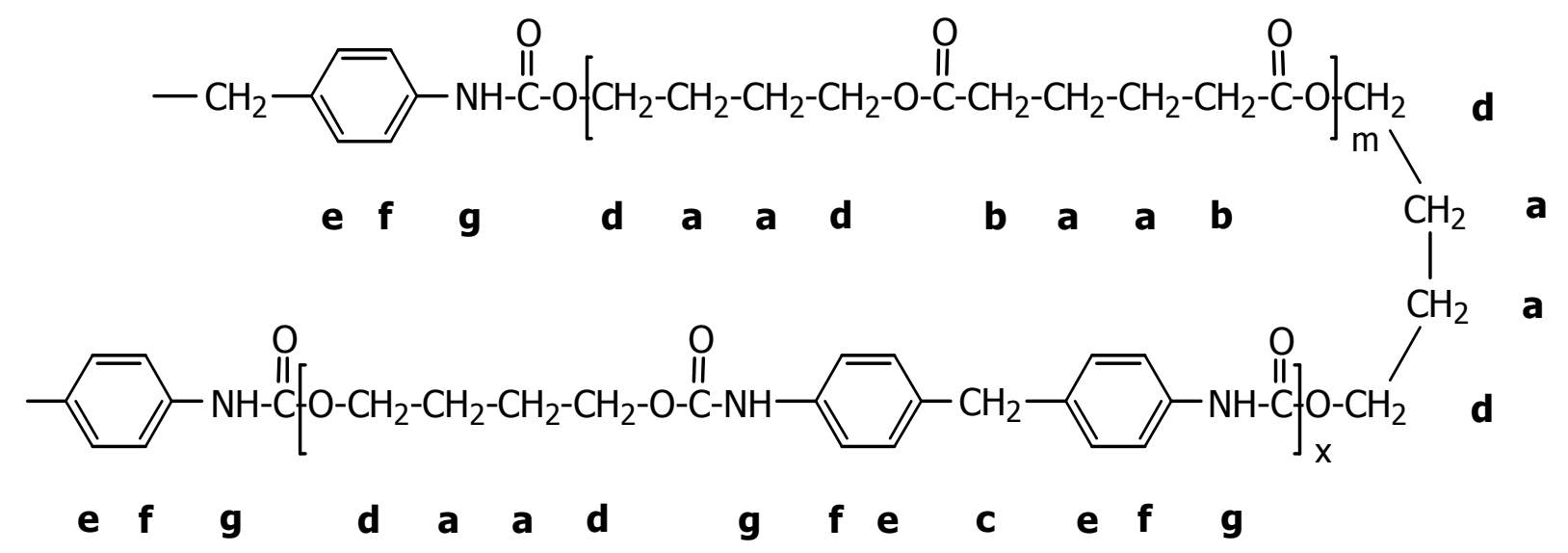

Figure 3: Proposed chemical structure for the starting TPU 

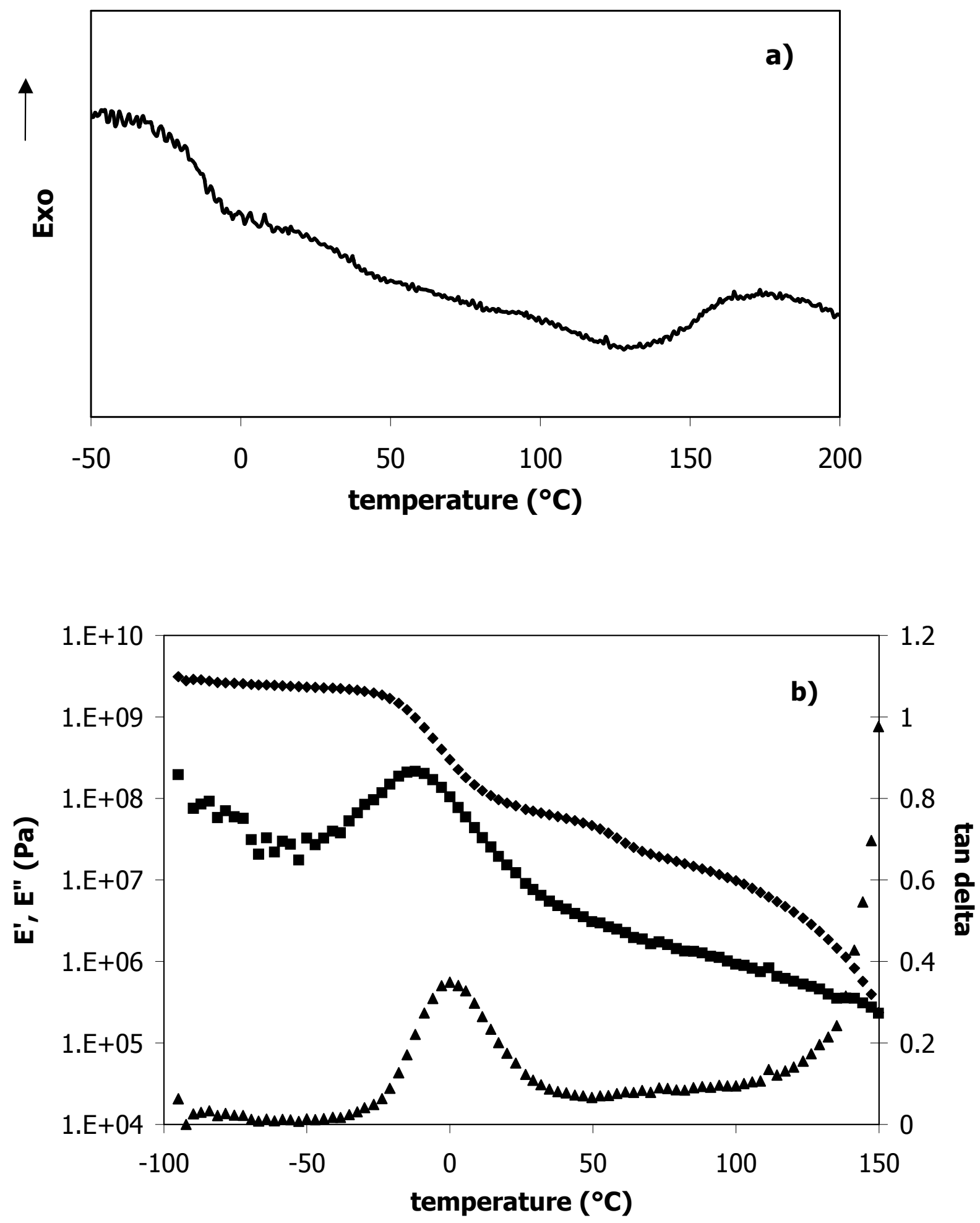

Figure 4: DSC analysis [a), $10^{\circ} \mathrm{C} / \mathrm{min}$ ] and dynamic mechanical properties [b), $1 \mathrm{~Hz}$, $3^{\circ} \mathrm{C} / \mathrm{min}$ ] of the raw TPU ( $\left.\bullet: \mathrm{E}^{\prime} ; \mathbf{\square}: \mathrm{E}^{\prime \prime} ; \mathbf{\Delta}: \tan { }^{*}\right)$ 


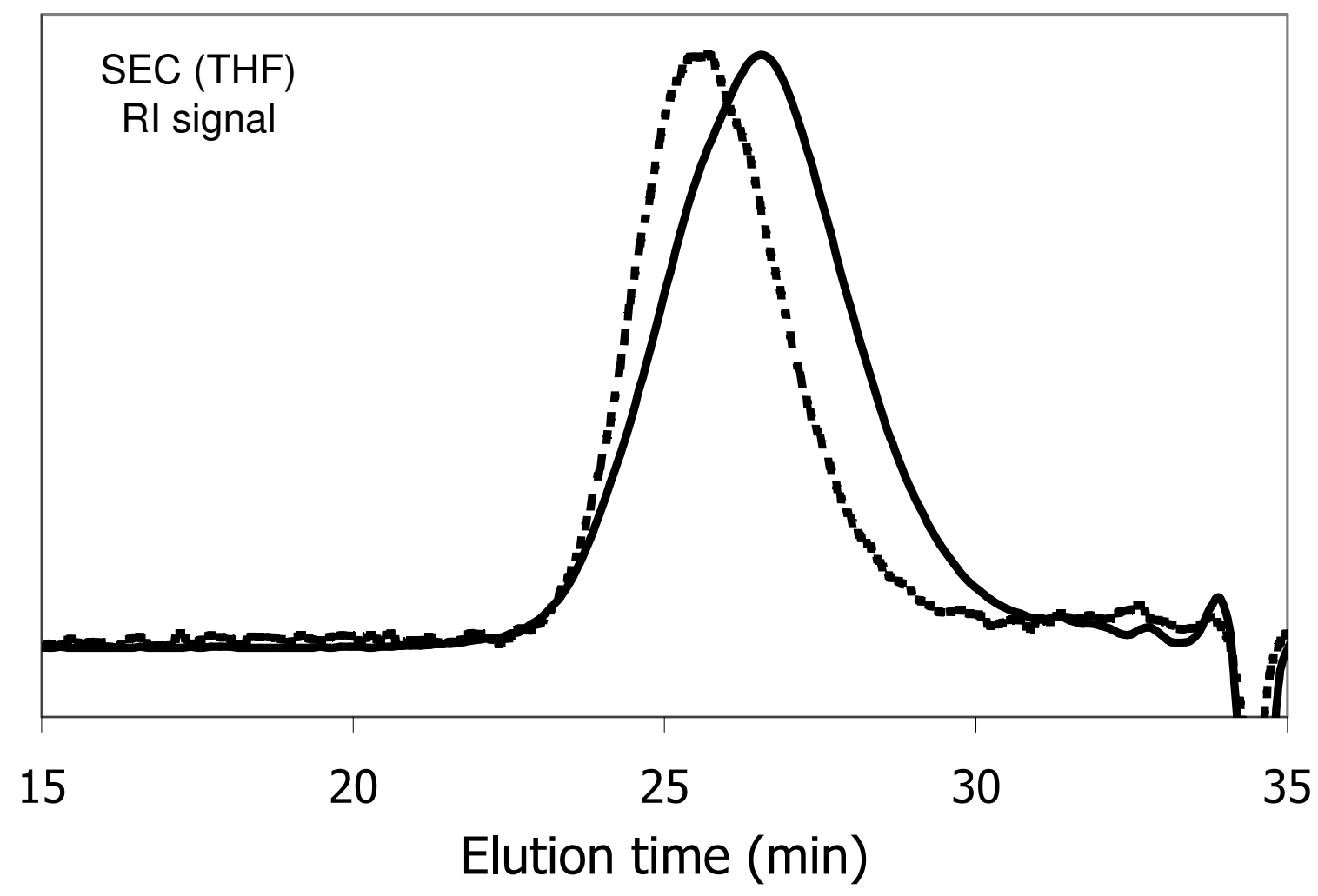

Figure 5: Size exclusion chromatograms (THF, RI detection) of the starting TPU (- - -) and of the TPU reacted with $\cdot$-APS alone $\left(170^{\circ} \mathrm{C}, 5 \mathrm{~min}\right)\left(\_\right)$ 


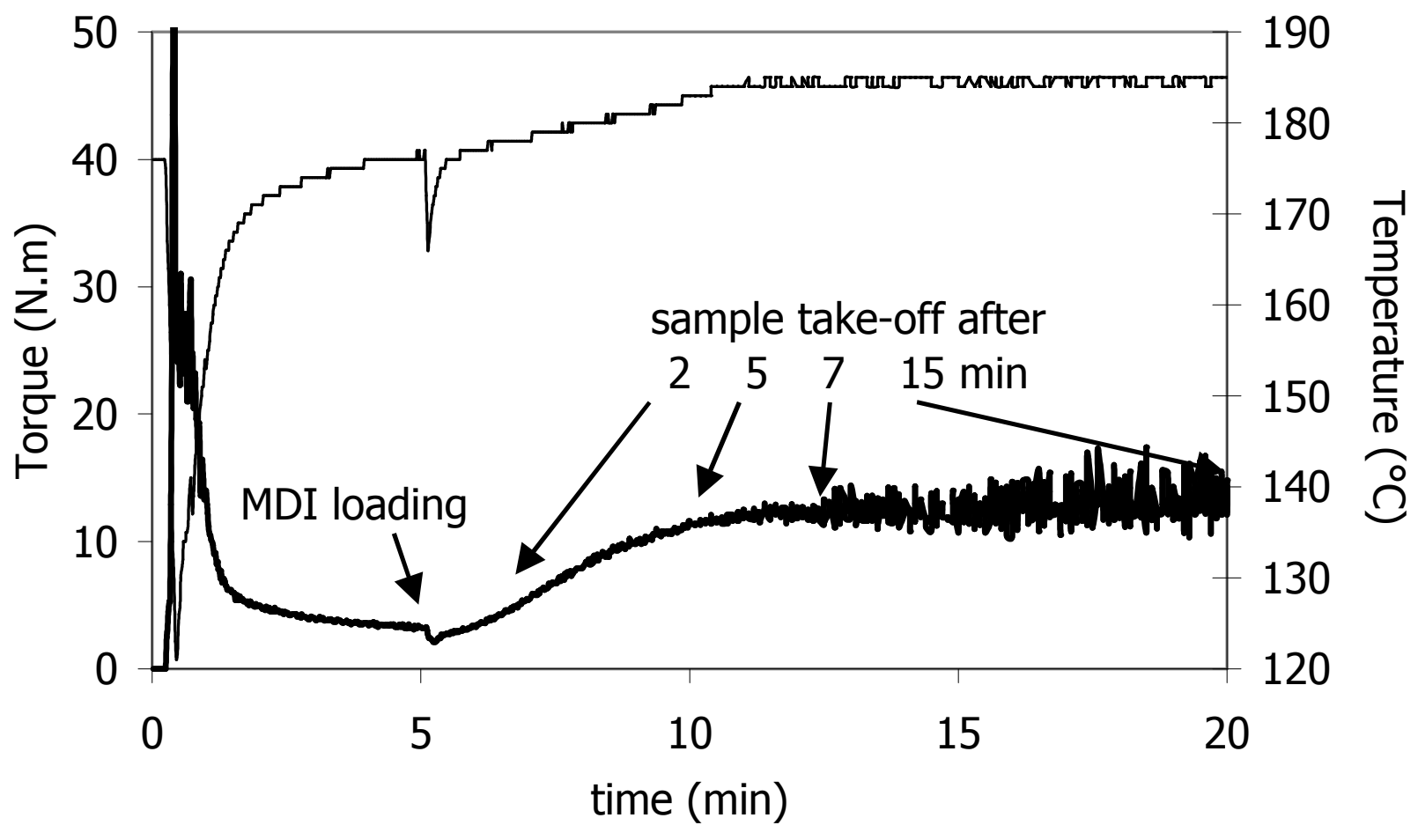

Figure 6: Material temperature $(-)$ and torque (-) variation observed during the reaction of TPU with MDI $\left([\mathrm{NCO}]_{0} /[\text { urethane }]_{0}=0.107 ; 170^{\circ} \mathrm{C} ; 30 \mathrm{rpm}\right)$ in the Haake plastograph 


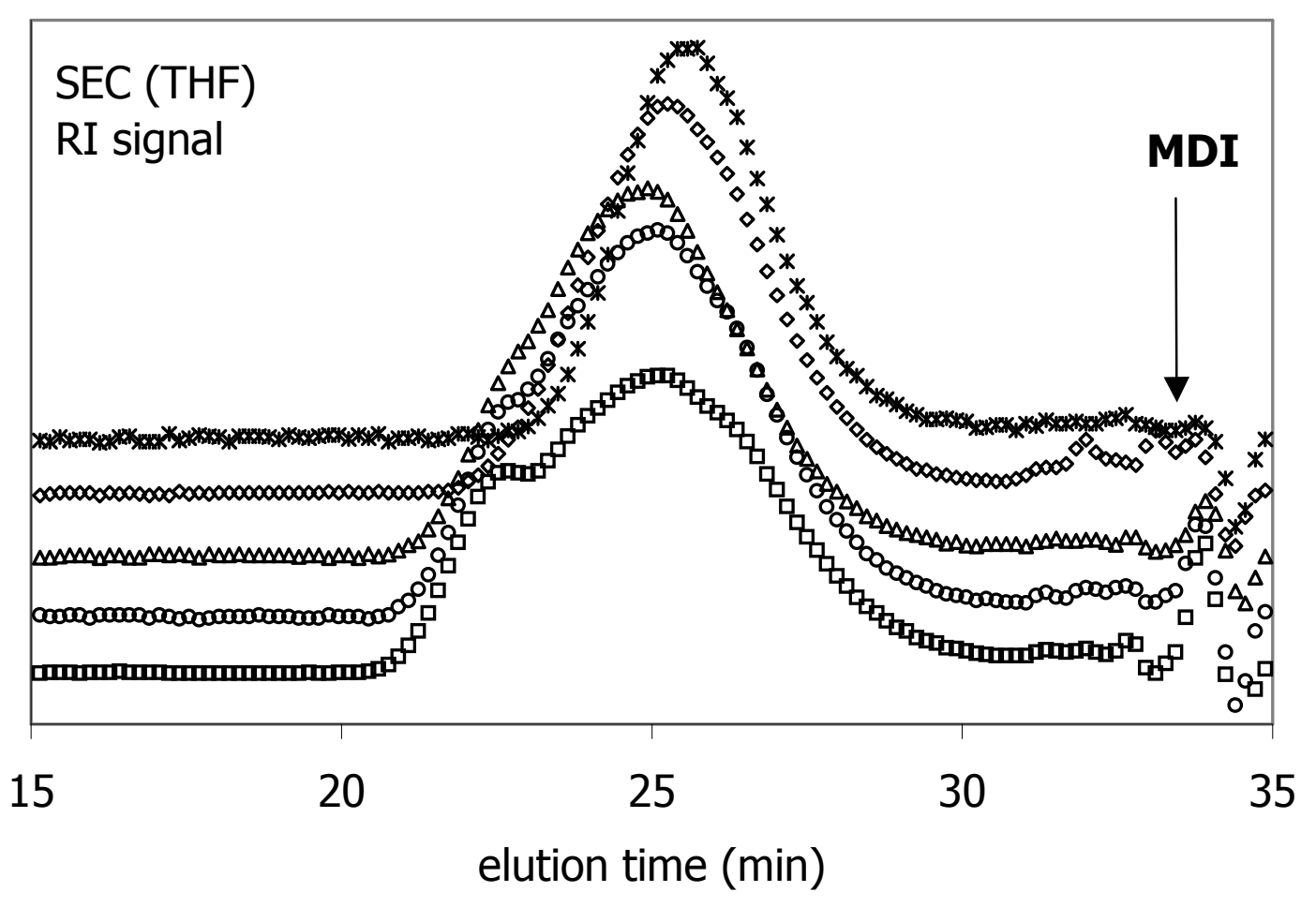

Figure 7: Size exclusion chromatograms of the initial TPU $(*)$ and of the TPU reacted with MDI $\left([\mathrm{NCO}]_{0} /[\text { urethane }]_{0}=0.107 ; 170^{\circ} \mathrm{C} ; 30 \mathrm{rpm}\right)$ for $(\diamond): 2 \mathrm{~min} ;(\Delta): 5 \mathrm{~min} ;(\circ): 7 \mathrm{~min}$; (): $15 \mathrm{~min}$; this last sample has only $80 \%$ soluble fraction. 


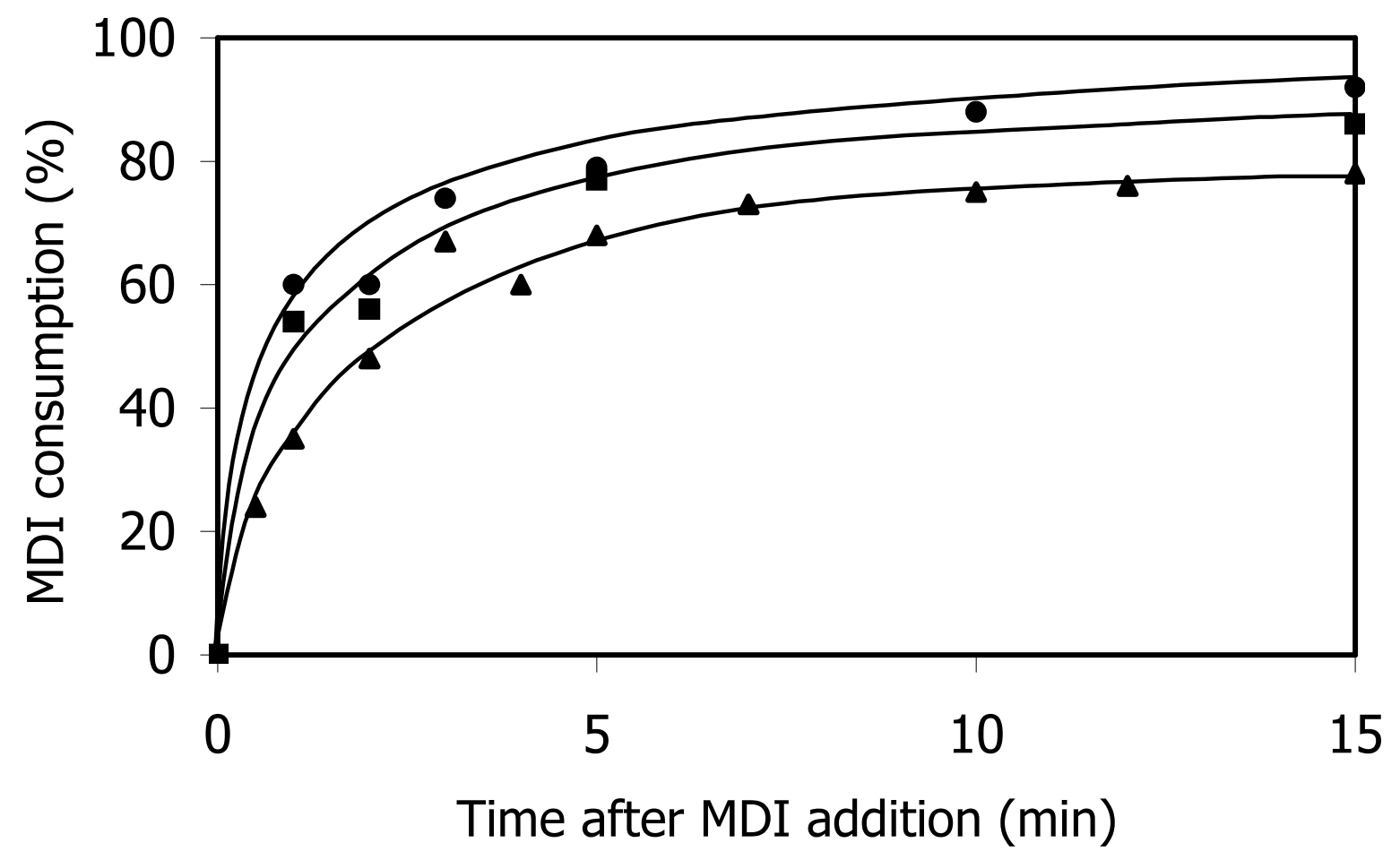

Figure 8: Conversion of MDI molecules deduced from the decrease in the DBA-MDI-DBA adduct peak in size exclusion chromatograms. Reaction temperature: $170^{\circ} \mathrm{C} ; \boldsymbol{\Delta}: 30 \mathrm{rpm}$; ๘ : $60 \mathrm{rpm} ; \bullet: 100 \mathrm{rpm}$. 

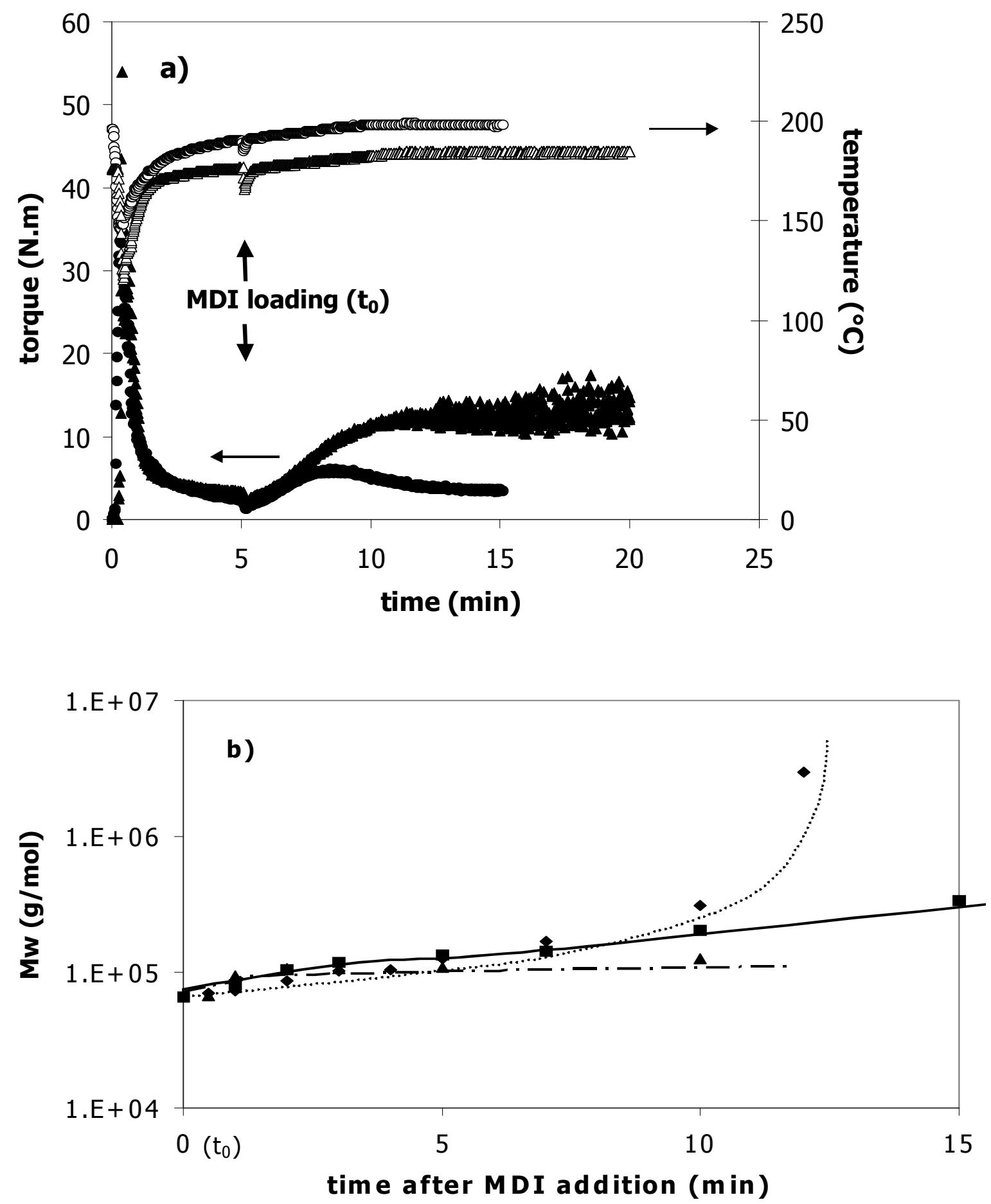

Figure 9: Effect of the assigned temperature on the grafting of TPU chains with MDI $\left([\mathrm{NCO}]_{0} /[\text { urethane }]_{0}=0.107 ; 30 \mathrm{rpm}\right):$ a) variation of the torque $\left(\mathbf{\Lambda}: 170^{\circ} \mathrm{C} ; \bullet: 190^{\circ} \mathrm{C}\right)$ and internal temperature $\left.\left(\triangle: 170^{\circ} \mathrm{C} ; \mathrm{O}: 190^{\circ} \mathrm{C}\right) ; \mathrm{b}\right)$ variation of the mass average molar mass $\left(\ldots \bullet \ldots: 170^{\circ} \mathrm{C} ;-\square: 180^{\circ} \mathrm{C} ; .-. \mathbf{\Lambda}-.: 190^{\circ} \mathrm{C}\right)$. 


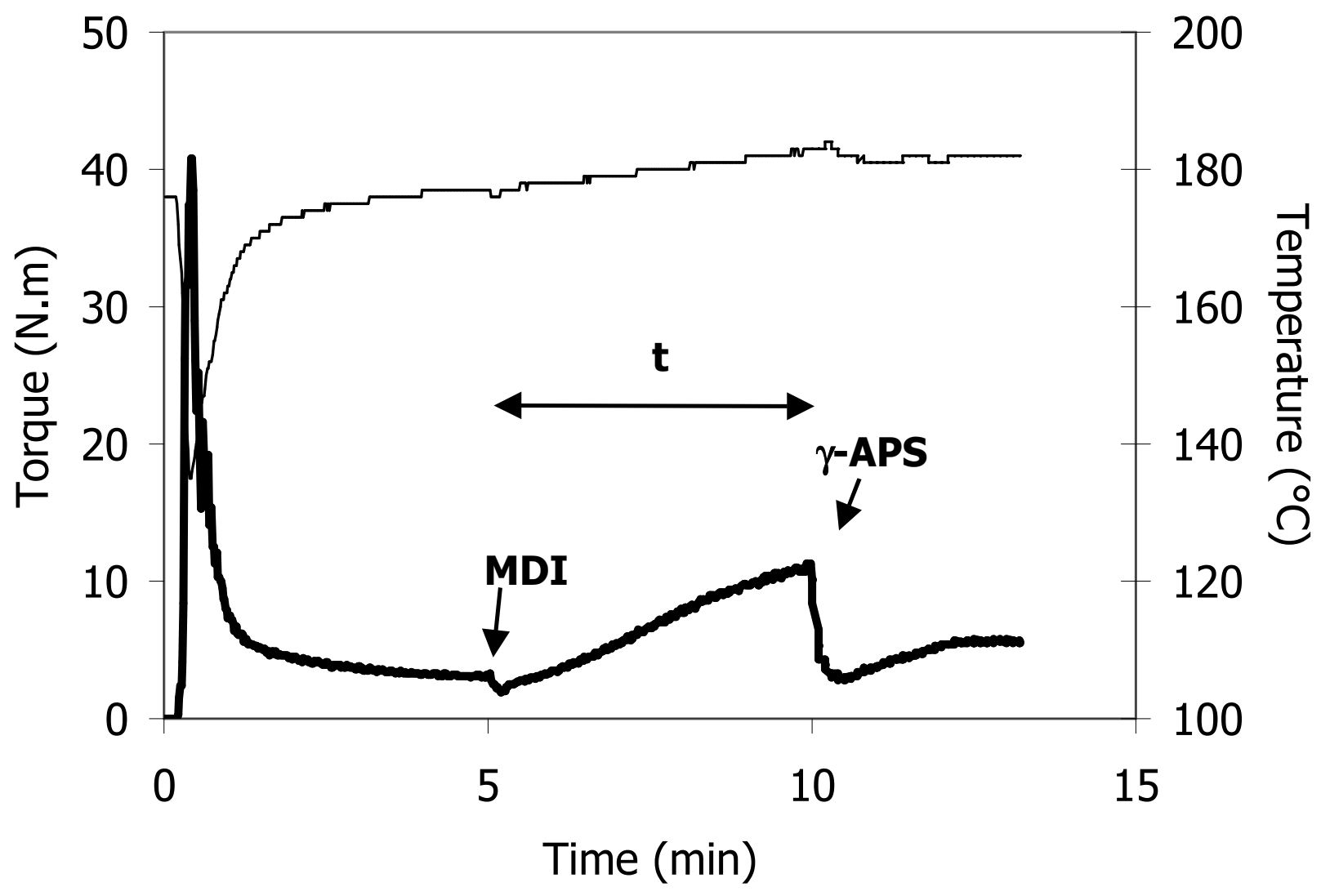

Figure 10: Material temperature $(-)$ and torque $(-)$ variation observed during the successive additions of MDI $\left([\mathrm{NCO}]_{0} /[\text { urethane }]_{0}=0.107\right)$ and $\cdot-$ APS $\left([\text { amine }]_{0} /[\text { urethane }]_{0}\right.$ $=0.053)$ to the raw $\mathrm{TPU}$ in the Haake plastograph $\left(170^{\circ} \mathrm{C} ; 30 \mathrm{rpm}\right)$ 


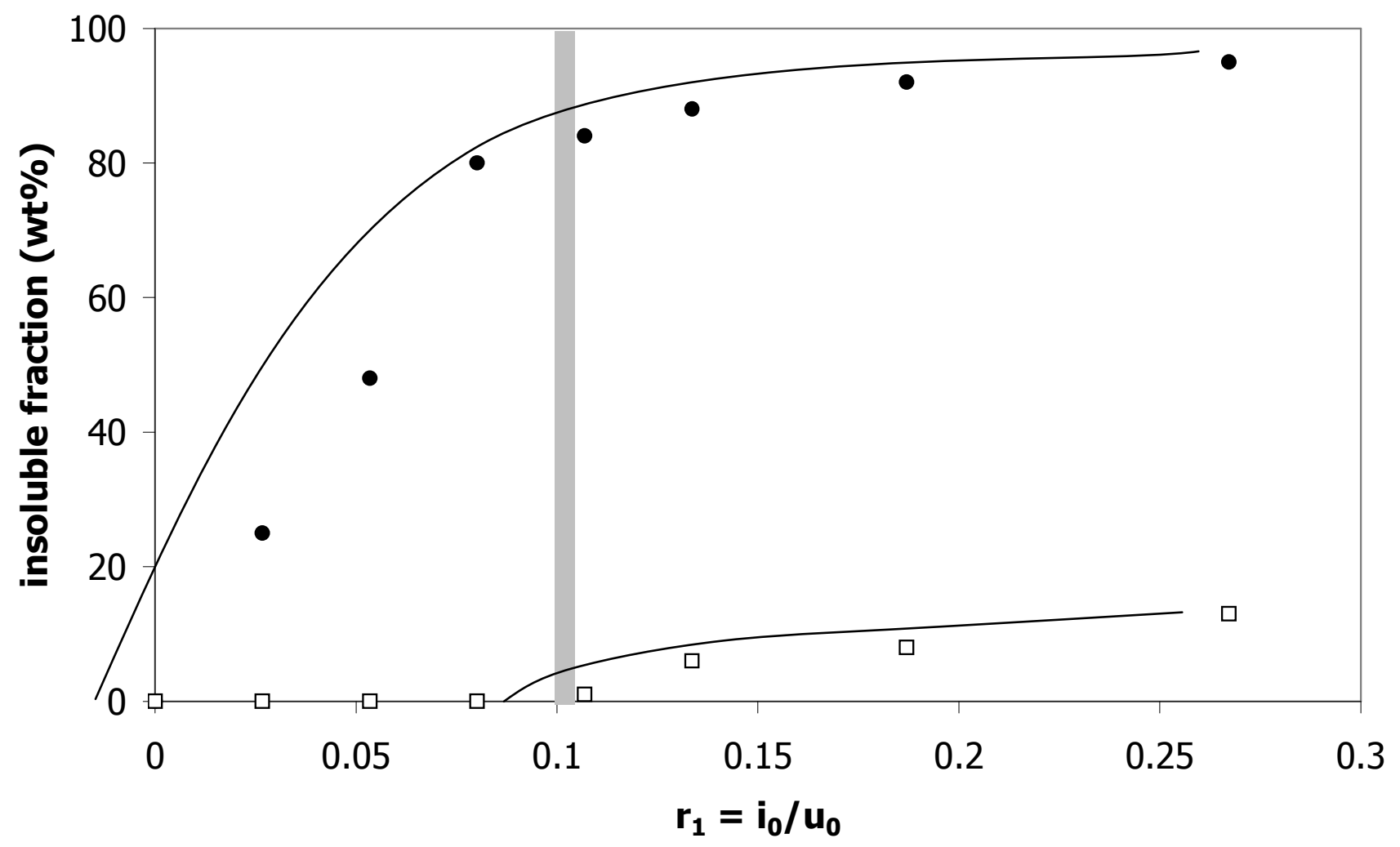

Figure 11: Insoluble fraction obtained for the TPU reacted successively with MDI and --APS $\left(r_{2}=2,170^{\circ} \mathrm{C}, 30 \mathrm{rpm}\right)$ using varying $r_{1}$ values, after : $(\square)$ : press molding $\left(170^{\circ} \mathrm{C}, 4 \mathrm{~min}\right)$; $(\bullet)$ press molding (same conditions), then hydrolysis and condensation of the alkoxysilane groups $\left(70^{\circ} \mathrm{C}, 95 \% \mathrm{RH}, 7\right.$ days). The gray area indicates the optimal $r_{1}$. 


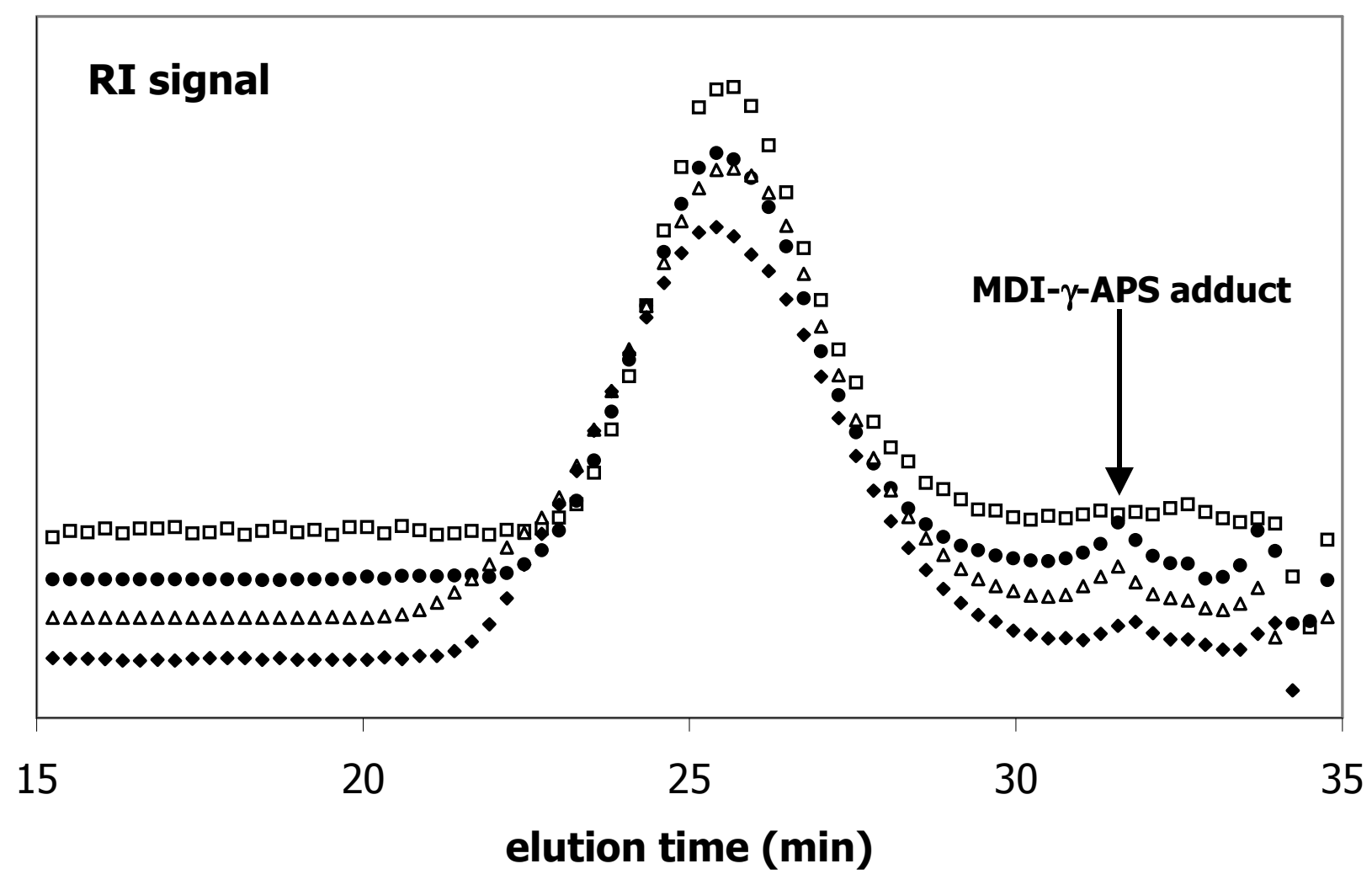

Figure 12: Size exclusion chromatograms of the starting TPU ( $\square$ ) and of the TPU reacted $\left(170^{\circ} \mathrm{C}, 30 \mathrm{rpm}\right)$ successively with MDI $\left(r_{1}=0.107\right)$ and $\cdot-$ APS $\left(r_{2}=2\right)$ added after $t=(\bullet)$ : $2 \min ;(\Delta): 5 \min ;(\bullet): 7 \min$. 


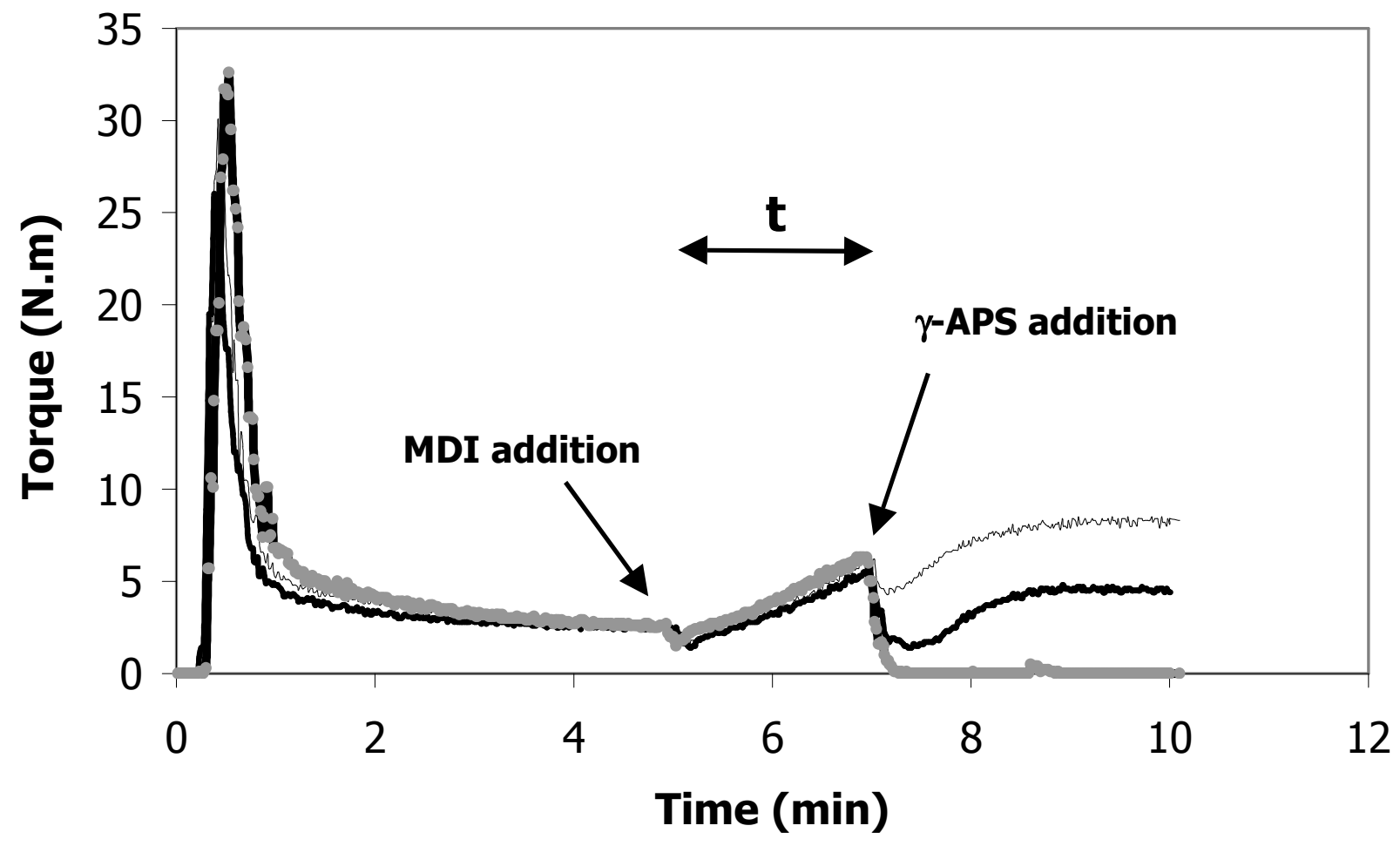

Figure 13: Torque variations recorded during the reaction of the TPU $\left(170^{\circ} \mathrm{C}, 30 \mathrm{rpm}\right)$ successively with MDI $\left(r_{1}=0.107, t=2 \min \right)$ and $\cdot-$ APS; $(-): r_{2}=4 ;(-): r_{2}=2 ;(\bullet \bullet \bullet)$ $: r_{2}=4 / 3$ 


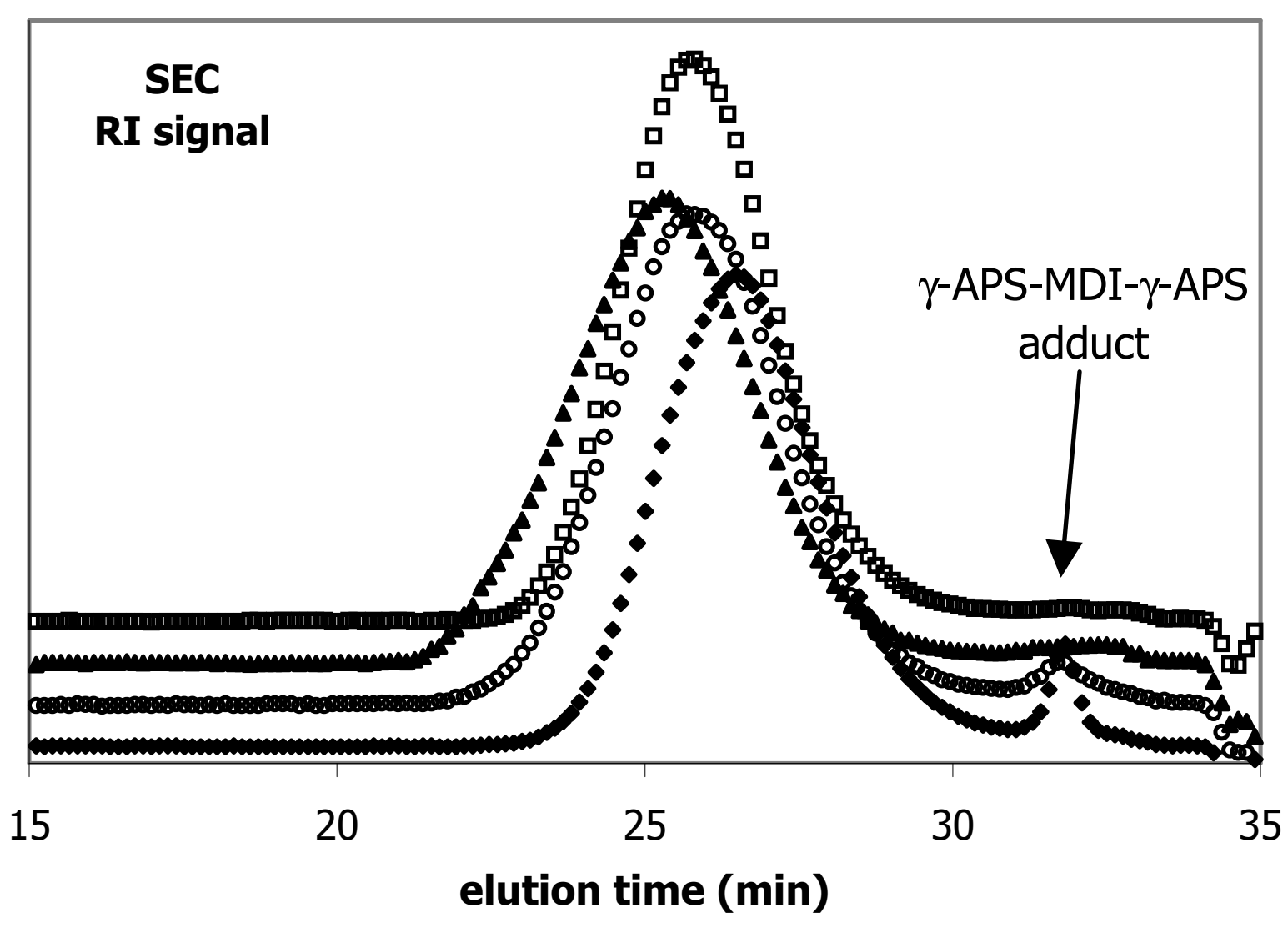

Figure 14: Size exclusion chromatograms of the starting TPU ( $\square$ ) and of this TPU reacted in the plastograph $\left(170^{\circ} \mathrm{C}, 30 \mathrm{rpm}\right)$ successively with MDI $\left(r_{1}=0.107, t=2 \mathrm{~min}\right)$ and $\cdot-$ APS; (A) $: r_{2}=4 ;(\circ): r_{2}=2 ;(\bullet): r_{2}=4 / 3$ 


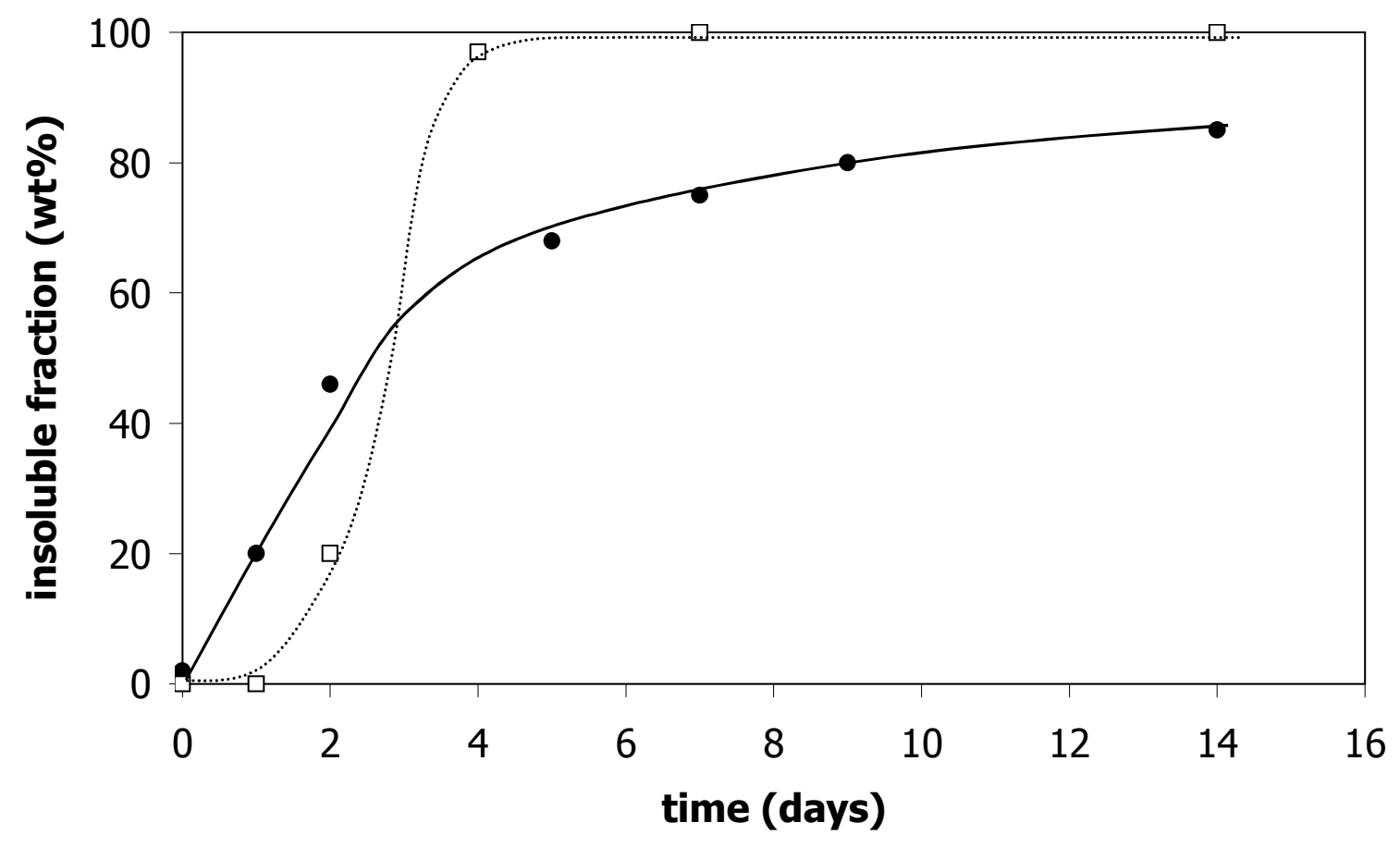

Figure 15: Insoluble fractions obtained for the TPU grafted with MDI and --APS $\left(r_{1}=\right.$ $\left.0.107 ; r_{2}=2, t=2 \mathrm{~min}\right)$ during hydrolytic condensation $\left(-\bullet, 70^{\circ} \mathrm{C}, 95 \% \mathrm{RH}\right)$. Comparison with a MDI-grafted TPU $\left(r_{1}=0.107\right)$ under room atmosphere $(\ldots . . \ldots$.$) .$ 

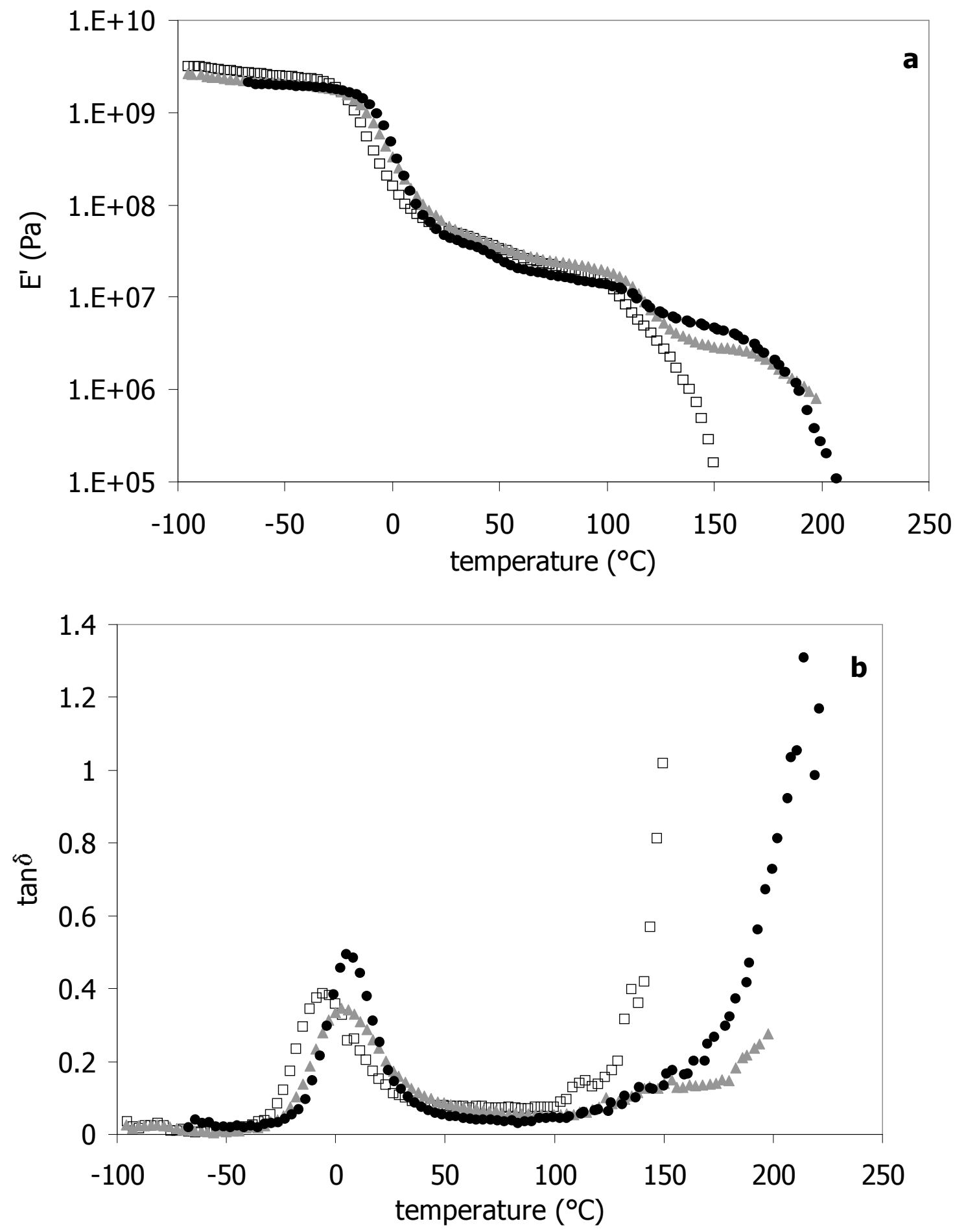

Figure 16: Storage moduli (a) and loss factors (b) of the starting TPU aged 7 days at $\left(70^{\circ} \mathrm{C}\right.$, 95\%RH) ( $\square)$, of the TPU grafted with MDI $\left(r_{1}=0.107\right)$ and hydrolyzed under room atmosphere $(\bullet)$, and of the TPU grafted successively with MDI and $\cdot-$ APS $\left(r_{1}=0.107, r_{2}=2\right.$, $\mathrm{t}=2 \mathrm{~min})$ and hydrolyzed $\left(70^{\circ} \mathrm{C}, 95 \% \mathrm{RH}, 7\right.$ days $)(\boldsymbol{\Delta})$. 


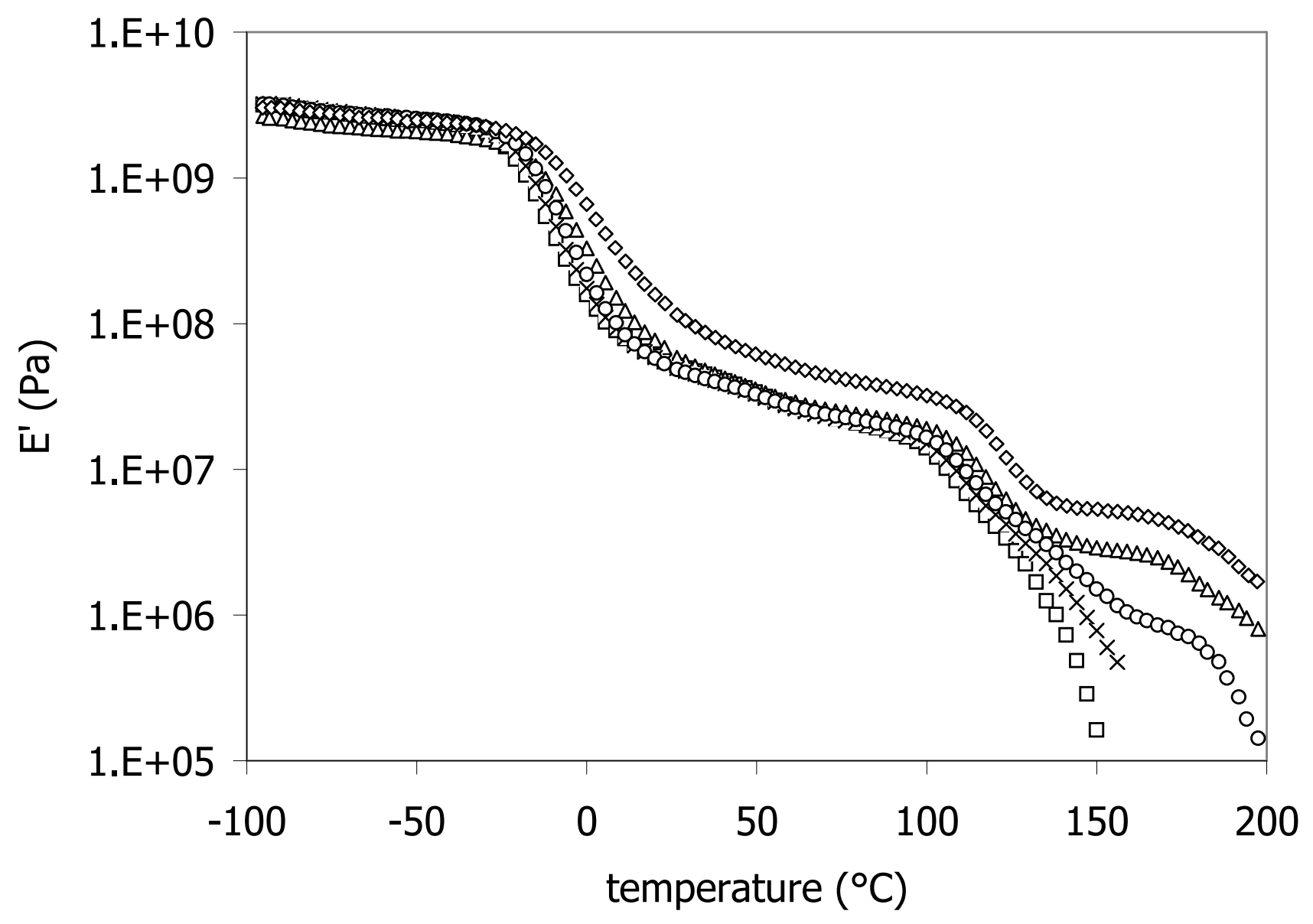

Figure 17: Storage moduli of the starting TPU aged 7 days at $\left(70^{\circ} \mathrm{C}, 95 \% \mathrm{RH}\right)(\square)$ and of the TPU grafted successively with MDI and --APS $\left(r_{2}=2\right)$ using increasing amounts of modifier. Per kg TPU: $(x)$ : $0.04 \mathrm{~mol}$ MDI or --APS ( $\left.r_{1}=0.027\right) ;(\circ): 0.08 \mathrm{~mol}\left(r_{1}=0.054\right)$; $(\Delta): 0.16 \mathrm{~mol}\left(r_{1}=0.107\right) ;(\diamond): 0.40 \mathrm{~mol}\left(r_{1}=0.268\right)$ 